Revista lus et Praxis, Año 20, No 2, 2014, pp. 307 - 356

ISSN 0717 - 2877

Universidad de Talca - Facultad de Ciencias Jurídicas y Sociales

"División de sociedades y sucesión universal"

Marcelo Mardones Osorio

Trabajo recibido el 2 de diciembre de 2013 y aprobado el 5 de marzo de 2014

\title{
División de sociedades y sucesión universal
}

CORPORATE DIVISION AND UNIVERSAL SUCCESSION

Marcelo Mardones Osorio*

Resumen

En el presente trabajo se analiza la comprensión de que, manera general, los organismos reguladores y la doctrina nacional poseen en relación a la operación de modificación estructural denominada división de sociedades. En dicho análisis, se cuestiona la comprensión tradicional de la división societaria como una asignación de cuotas preexistentes de una universalidad, postulando que en nuestro país, siguiendo las experiencias comparadas, es posible -y necesariocomprender la división de sociedades como una operación de modificación estructural en cuya virtud se opera el traspaso uno actu e in universum ius de porciones patrimoniales en virtud de la técnica de la sucesión universal parcial.

\section{ABSTRACT}

This paper discusses the general understanding of regulators and national doctrine regarding the structural modification operation called corporate division. In this analysis, we question the traditional understanding of the corporate division as the allocation of preexisting quota of a totality, postulating that in Chile, following the comparative experiences, it is possible -and necessary-to understand the division of societies as an structural modification operation whereby operates the transfer uno actu and in universum ius in virtue of the technique of partial universal succession (by operation of the law).

Palabras Clave

División de sociedades, Sucesión universal, Sucesión universal parcial

KEYWORDS

Corporate Division, Universal succession, Partial universal succession

\section{Introducción}

En Chile, la concepción tradicional de la división de sociedades se estructura sobre el principio de que las partes que resultan de dicho proceso en conjunto han de ser iguales al todo que se trata de dividir. Dicho principio se manifiesta esencialmente en dos aspectos. Por una parte, el capital y el patrimonio de las nuevas sociedades provienen única y exclusivamente del capital y el patrimonio

\footnotetext{
*Abogado en Aylwin Abogados (Santiago, Chile). Doctor (c) en Derecho (Pontificia Universidad Católica de Chile), Magíster en Ciencias Jurídicas (Pontificia Universidad Católica de Chile), Máster en Asesoría Jurídica de Empresas (IE Law School, España). Correo electrónico: mmardones@aylwinabogados.cl.
} 
de la sociedad que se divide. Y por la otra, los socios de las nuevas sociedades son socios también de la sociedad que se divide. Como consecuencia de dicha construcción se sostiene que en una operación de división societaria nos encontramos ante una verdadera adjudicación de cuotas de una universalidad de Derecho, y en ningún caso ante una enajenación (transferencia o transmisión) de bienes a favor de las nuevas sociedades. De ello se desprende que la división societaria no sería título traslaticio de dominio, sino que se trataría de un mero título declarativo de un derecho preexistente, por lo que no sería necesario realizar la tradición para adquirir el dominio u otros derechos reales o personales sobre los bienes que se integran en las nuevas sociedades ${ }^{1}$.

Tal conceptualización implica una aplicación analógica de las reglas generales de partición de bienes comunes, en tanto que el comunero adjudicatario es dueño del bien adjudicado desde el día en que se originó la comunidad, por lo que en tal caso la adjudicación no tendría efecto atributivo sino que meramente declarativo de un derecho preexistente.

Según nuestro parecer esta concepción de la división es cuestionable, en tanto que implica una extensión analógica al ámbito mercantil de una institución propia del Derecho Común. El explicar la división de sociedades acudiendo a las reglas civiles sobre partición es una incongruencia, por cuanto vacía de contenido la norma especial del artículo 94 de la Ley No 18.046, sobre Sociedades Anónimas (en adelante, LSA). La supuesta asignación de derechos preexistentes requiere necesariamente para su reconocimiento -y por lo tanto para atribuir efectos declarativos a la división- partir de la base de la existencia de una comunidad previa, en la cual efectivamente existen dichos derechos, indeterminados en su cuota, los que se determinan/especifican, por medio de la correspondiente adjudicación -división- a los comuneros. Sólo en este caso la adjudicación sería mero título declarativo, ya que si ésta se realiza a favor de un tercero no comunero estamos ante una enajenación ${ }^{2}$, y en consecuencia, la transferencia de los bienes debe realizarse de conformidad con las reglas generales previstas por las distintas leyes reguladoras. En la división societaria no cabe referirse a una comunidad previa que sea objeto de división. Lo que se divide es el patrimonio de una sociedad en el cual no existe comunidad alguna. Por lo tanto, llevada la argumentación expuesta a sus últimas consecuencias, sería posible concluir que en la división de sociedades existiría una enajenación de una parte del patrimonio de la sociedad original, la cual requeriría cumplir con cada una de las normas de circulación de los distintos bienes que integran

1 Véase en este sentido, el Of. № 2.048, de 1989, de la SVS; y el fallo de fecha 22 de noviembre de 2012, Rol No 8354-2011, de la Corte Suprema.

2 Alessandri (1984), p.155; LiRA (1948), pp. 201-202. 
el patrimonio escindido, lo cual es enteramente opuesto a lo que es la esencia de la institución.

Por lo expuesto, parece inapropiado extender analógicamente a la división societaria las normas sobre partición de comunidades, tanto por la inexistencia de una identidad en los supuestos de hecho que justifique tal extensión (la comunidad es un cuasicontrato y la sociedad es un contrato) como por la imposibilidad de que dichas normas civiles den correcta solución a los requerimientos del tráfico mercantil moderno, que exige la posibilidad de dividir los patrimonios sociales de manera rápida, flexible y segura.

En mérito de las consideraciones expuestas, cabe plantearse al menos dos cuestiones, a saber: (i) si en la operación de división de sociedades anónimas es posible sostener la existencia de una verdadera sucesión universal, tal y como se contempla en el Derecho comparado ${ }^{3}$, a fin de reemplazar la actual fundamentación de dicha operación, y; (ii) si considerándose que existe sucesión universal, es posible extender la misma a las operaciones de división que no cuentan con sustento positivo, es decir, a los casos de división total de sociedades anónimas y a los supuestos de división de sociedades de personas, sobre la base del principio de autonomía de la voluntad. A ello nos abocaremos seguidamente.

\section{Evolución de la división de sociedades en el ordenamiento jurídico chileno}

\subsection{Orígenes normativos en el Derecho comparado}

Es usual en la doctrina ${ }^{4}$ sostener que la escisión o división societaria encuentra sus orígenes básicamente en los ordenamientos francés e italiano de mediados del siglo XX. Sin embargo, dicha operación fue consagrada positivamente por primera vez en los Estados Unidos, en la Revenue Act del año 1918, aunque tal regulación era de naturaleza eminentemente tributaria. Dicho texto dispuso en su sección 202.(b) una excepción al régimen normal de tributación de cambios de acciones como consecuencia de reorganizations, mergers y consolidations, regulando así por primera vez las denominadas corporate reorganizations ${ }^{5}$. En

\footnotetext{
3 Así, en el Derecho Comunitario Europeo, el artículo 17.1 letra a) de la Sexta Directiva del Consejo, de 17 de diciembre de 1982, basada en la letra g) del apartado 3 del artículo 54 del Tratado y referente a la escisión de sociedades anónimas, establece que "La escisión produce ipso iure y simultáneamente los siguientes efectos: a) la transmisión, tanto entre la sociedad escindida y las sociedades beneficiarias como con respecto a terceros, de la totalidad del patrimonio activo y pasivo de la sociedad escindida a las sociedades beneficiarias;".

${ }^{4}$ Duque (1978), pp. 128-130; Otaegui (1981), pp. 238-239; Martín (2008), pp. 122-124; Cabanellas (2009), p. 124.

${ }^{5}$ EisenBerg (1969), p. 105. El artículo era del siguiente tenor: "(b) When property is exchanged for other property, the property received in exchange shall for the purpose of determining gain or
} 
materia de división de sociedades, la Revenue Act de 1918 recogía la operación denominada split-up (escisión total) ${ }^{6}$, consistente en la distribución de la totalidad de los activos de la matriz, entre dos o más subsidiarias, cesando aquella su operación y entregando a sus socios las acciones de las subsidiarias. Posteriormente, la Revenue Act de 1924 incorporó la regulación de las otras dos formas de escisión parcial conocidas en el Derecho norteamericano: las spin-offs, consistentes en la distribución a pro-rata de acciones que una matriz efectúa a sus socios, de las acciones que posee de su subsidiaria, como consecuencia de haber aportado a ésta determinada porción de actividad (se trata de una especie de dividendo in natura); y las split-offs, consistentes en la distribución non pro-rata de acciones que una matriz efectúa a sus socios, de las acciones que posee de su subsidiaria, a cambio de acciones de los socios de la matriz (es decir, con canje de acciones) o a cambio de deuda ${ }^{7}$.

En Francia, la práctica societaria de escisiones habría comenzado entre los años 1949 y 1952, sin fundamento normativo expreso. En virtud de dicha práctica y sobre la base de necesidades económicas, la operación fue administrativamente reconocida en el ámbito tributario, al hacer extensible a las escisiones parciales el régimen fiscal de las fusiones, siendo asimismo aceptada por los máximos tribunales franceses ${ }^{8}$. Positivamente, el Décret $N^{\circ}$ 54-1226 du 7 décembre 1954, publicado en el Journal Officiel de 10 de diciembre del mismo año, incorporó al ordenamiento jurídico-positivo francés la primera alusión a la escisión de sociedades, al modificar el artículo $3^{\circ}$ de la Loi sur

loss be treated as the equivalent of cash to the amount of its fair market value, if any; but when in connection with the reorganization, merger, or consolidation of a corporation a person receives in place of stock or securities owned by him new stock or securities of no greater aggregate par or face value, no gain or loss shall be deemed to occur from the exchange, and the new stock or securities received shall be treated as taking the place of the stock, securities, or property exchanged. When in the case of any such reorganization, merger or consolidation the aggregate par or face value of the new stock or securities received is in excess of the aggregate par or face value of the stock or securities exchanged, a like amount in par or face value of the new stock or securities received shall be treated as taking the place of the stock or securities exchanged, and the amount of the excess in par or face value shall be treated as a gain to the extent that the fair market value of the new stock or securities is greater than the cost (or if acquired prior to March 1, 1913, the fair market value as of that date) of the stock or securities exchanged."

${ }^{6}$ WolfF (1953), p. 716.

7 JACOBS (1967), pp. 3-4; EISENBERG (1969), p. 174. En la tramitación parlamentaria de la Revenue Act de 1924 se dejó constancia de que la modificación entonces en trámite tuvo por objeto "(...) to include other usual forms of corporate reorganization in the advance of business, such as the splitting of one corporation into two or more corporations, which I may say under the present law would not be permitted except by forming two entirely new corporations". BANK (2004), p. 1171.

${ }^{8}$ Duque (1978), p. 128; Otaegui (1981), p. 238. Aceptando dicha práctica, los fallos de la Cour de Cassation de fecha 20 de junio de 1966 y de 7 de diciembre de 1966. 
les sociétés en commandite par actions, anonymes et coopératives, de 24 de julio de 1867, aunque sin hacer referencia expresa a la escisión, sino que al caso de "(...) aporte por una sociedad de parte de sus elementos del activo a otra sociedad" ${ }^{\prime \prime}$, para contemplarlo como una excepción a la regla general de no negociabilidad por un período de dos años de las acciones emitidas por las sociedades de capital. Posteriormente, el inciso $2^{\circ}$ del artículo 371 de la Loi $N^{\circ}$ 66-537 du 24 juillet 1966 sur les sociétés comerciales reconoció en forma expresa la escisión de sociedades, disponiendo que "Une société peut aussi, par voie de scission, transmettre son patrimoine à plusieurs sociétés existantes ou à plusieurs sociétés nouvelles".

En Italia, si bien la escisión de sociedades sólo se incorporó a su Derecho positivo con el Decreto legislativo $N^{\circ} 22 / 1991^{10}$, que traspuso en el ordenamiento jurídico italiano las directivas comunitarias sobre fusiones $\left(3^{a} \text { Directiva }\right)^{11}$ y escisiones $\left(6^{a} \text { Directiva }\right)^{12}$, la discusión doctrinal sobre la viabilidad jurídica de la operación comenzó con un fallo de la Corte de Apelaciones de Génova, de fecha 9 de febrero de $1956^{13}$. En dicho fallo, la Corte estimó que aun cuando el ordenamiento positivo italiano no contemplaba

9 RECORDON (1974), pp. 30-31. El inciso $5^{\circ}$ del nuevo artículo $3^{\circ}$ señalaba que "En cas de fusion de
sociétés par voie d'absorption ou de création d'une société nouvelle englobant une ou plusieurs socié-
tés préexistantes ainsi qu'en cas d'apport par une société de partie de ses éléments d'actif a une autre
société, l'interdiction de détacher les actions et de les négocier ne s'applique pas aux actions d'apport
attribuées à une société par action ayant, lors de la fusion ou de l'apport, plus de deux ans d'existence,
lorsque-les biens compris dans l'apport-fusion ou dans l'apport partiel auquel correspondent les actions
attribuées étaient précédemment représentées par des actions négociables".

10 Campobasso (2002), p. 325; Sarale (2011), p. 601.

11 Tercera Directiva 78/855/CEE del Consejo, de 9 de octubre de 1978, basada en la letra g) del apartado 3 del artículo 54 del Tratado y relativa a las fusiones de las sociedades anónimas, cuya versión actual se contiene en la Directiva 2011/35/UE del Parlamento Europeo y del Consejo de 5 de abril de 2011, relativa a las fusiones de las sociedades anónimas.

12 Sexta Directiva 82/891/CEE del Consejo, de 17 de diciembre de 1982, basada en la letra g) del apartado 3 del artículo 54 del Tratado y referente a la escisión de sociedades anónimas. Para un análisis general de la evolución y estado actual del Derecho Europeo de Sociedades, EMBID (2013).

13 Fallo en Rivista del Diritto Commerciale, 1957, Año LV, No s. 1-2, marzo-abril, pp. 34-35, con nota de NobiL (1957) pp.35-39. El fallo surge como consecuencia del recurso de alzada interpuesto en contra de la sentencia del tribunal de Génova, de fecha 12 de diciembre de 1955, que negaba eficacia al acuerdo de la asamblea extraordinaria de una sociedad de responsabilidad limitada (denominada C.I.S.A.), relativo a: (i) la escisión parcial de dicha sociedad, en una nueva sociedad de responsabilidad limitada (denominada C.I.E.S.A.) con un capital social de 180.000 liras; (ii) la reducción del capital de C.I.S.A. desde 360.000 liras a 180.000 liras, y (iii) el aporte a la sociedad escindida de aproximadamente la mitad del patrimonio de la sociedad C.I.S.A. La denegación de eficacia se fundó en que la escisión de sociedades era una operación desconocida en el Derecho italiano vigente en aquel momento, considerándose que tal vacío contrastaba con el reconocimiento expreso que de la fusión se hacía en el Derecho positivo italiano. De ello, el tribunal desprendía la voluntad del legislador italiano de no aceptar ninguna especie de escisión de sociedades. 
la escisión de sociedades, la sociedad podía adoptar cualesquiera acuerdos que estimara adecuados a sus intereses, en virtud del principio de autonomía privada, que resultaba plenamente aplicable en la especie. Junto a ello, la Corte estimó que en la escisión en realidad existían dos actos que sí se encontraban reconocidos en el ordenamiento vigente: una reducción de capital (del capital "exuberante" o en exceso -artículo 2445 del Codice Civile-, tras el aporte a la nueva sociedad de parte de la actividad de la sociedad escindida) y la posterior creación de una nueva sociedad a la que se aportaba la suma equivalente a la reducción antes efectuada. Finalmente, la Corte señaló que la operación así comprendida no entrañaba peligro para terceros, ya que las reglas relativas a la reducción de capital exuberante contemplaban un derecho de oposición a favor de los acreedores sociales. A partir de dicho fallo, la discusión doctrinal se centró en dos aspectos esenciales: la posibilidad de que la sociedad escindente creara una nueva sociedad sin la concurrencia de otra parte, lo que minaba el elemento fundamental del contrato de sociedad -su plurilateralidad-; y la posibilidad de que los socios acordaran la creación de una sociedad (la escindida) en la que ellos formarían parte, la cual recibiría parte del patrimonio de la escindida, y por el cual los socios (y no la sociedad aportante) recibirían títulos de participación ${ }^{14}$.

En Alemania, el Derecho germano de modificaciones estructurales no trató de la división de sociedades (Spaltung), sino hasta la Umwandlungsgesetz (UmwG, o "Ley de Transformaciones", entendidas éstas en sentido amplio y no como mero cambio de tipo social) ${ }^{15}$, de fecha 28 de octubre de 1994 y en vigor desde el día $1^{\circ}$ de enero de 1995, sin perjuicio de la existencia de variadas discusiones doctrinales en cuanto a la posibilidad de realizar esta operación sin mediar soporte legal ${ }^{16}$. La ley de sociedades por acciones o Aktiengesetz (AktG) de 1937 regulaba sólo la fusión (\$233 y siguientes) y la transformación (§257 y siguientes) de sociedades de acciones entre ellas y con sociedades de responsabilidad limitada $(\mathrm{GmbH})$, derogándose lo establecido al efecto en los entonces vigentes $\$ 80$ y $\S 81$ de la ley de sociedades de responsabilidad limitada o Gesetz betreffend die Gesellschaften mit beschränkter Haftung $(\mathrm{GmbHG})$, de 1892. Sin perjuicio de ello, con fecha 5 de julio de 1934 se dictó la ley sobre transformación de sociedades de capital (Gesetz über die Umwandlung von Kapitalgesellschaften), que tuvo efectos sólo hasta el 31 de diciembre de 1936 y que permitió la fusión y transformación de sociedades de capital en sociedades de personas, estableciendo ciertos beneficios tri-

14 Nobili (1957), p. 37; Duque (1978), p. 129; Sarale (2011), pp. 602-603.

15 Embid (1991), p. 15; EMBID (1991 a), p. 294.

16 Duque (1978), pp. 128-129. 
butarios a tal fin. Junto con tales regulaciones coexistieron las disposiciones que al efecto contemplaban diversas leyes especiales, como la propia $A k t G$ de 1965, cuyos \$339 y siguientes regulaban la fusión; \$362 y siguientes la transformación de las sociedades por acciones en otros tipos de sociedades de capital; y $\$ 359$ y $\$ 360$, la cesión total o parcial del patrimonio social; en la UmwG de 1969 (que no se asimilaba a la actual UmwG), que regulaba la fusión y la transformación entre sociedades de capital y de personas; en la KapErhG de 1959 (Gesetz über die Kapitalerhohüng aus Gesellschaftsmitteln und über die Verschmelzung von Gesellschaften mit beschränkter Haftung o ley sobre aumentos de capital con recursos propios y de fusión de sociedades de responsabilidad limitada), la cual en el año 1980 incorporó normas para la fusión entre las $\mathrm{GmbH}$; en la propia $\mathrm{GmbHG}$, tras su modificación de 1980, que incorporó en su §56a la posibilidad de transformación de un comerciante individual en una $\mathrm{GmbH}$; en los $\$ 93$ a y siguientes de la GenG (Genossenschaftsgesetz o ley sobre sociedades cooperativas, de 1922), en los que se regulaba la fusión de cooperativas; y en la VAG (Gesetz über die Beaufsichtigung der Versicherungsunternehmen o ley sobre empresas mutuas de seguros); leyes ninguna de las cuales abordaba la escisión de sociedades, lo cual, en todo caso, no impidió la realización de divisiones, si bien por medio del expediente de las transferencias singulares de bienes ${ }^{17}$. Antes de la $U m w G$, sólo se efectuaron referencias normativas a la división societaria en la Ley de Ajuste Agrícola (Landwirtschaftsanpassungsgesetz o Gesetz über die strukturelle Anpassung der Landwirtschaft an die soziale und ökologische Marktwirtschaft in der Deutschen Demokratischen Republik-LwAnpG-), de 1990, y en la Ley sobre División de Empresas Administradas por la Agencia Fiduciaria -Treuhandanstalt- (Gesetz über die Spaltung der von der Treuhandanstalt verwalteten Unternehmen -SpTrUG-), de $1991^{18}$.

Finalmente, en Suiza, la escisión no se contempló positivamente sino hasta la entrada en vigor de la Loi fedérale sur la fusion, la scission, la transformation et le transfert de patrimoine (Loi sur la fusion, LFus), de 3 de octubre de 2003. Hasta dicha consagración, la doctrina mayoritaria estimaba que la escisión se encontraba prohibida, ya que implicaba una división y reducción del sustrato de responsabilidad de la sociedad ${ }^{19}$.

\footnotetext{
17 Eberhard (1999), p. 21.

18 Stengel (1995), p. 86; Maulbetsch (2008), p. 6; Dauner-Lieb (2009), p. 2. En España, León (1994), pp. 448-449.

${ }^{19}$ Véase al respecto el Messaggio a sostegno di una legge federale sulla fusione, la scissione, la trasformazione e il trasferimento di patrimonio, de 13 de junio de 2000, pp. 3767-3770; RECORDON (1974) p. 49.
} 


\subsection{La división de sociedades en el Derecho y doctrina chilena}

\section{a) Evolución positiva}

La escisión, denominada en nuestro ordenamiento jurídico como división por claro influjo del Derecho norteamericano ${ }^{20}$, ingresó por primera vez a aquél a través del ámbito tributario, por medio de la Ley $N^{\circ} 17.073$, de $1968^{21}$. Dicha norma sólo abordó sus efectos tributarios, sin contener una regulación sustantiva de la operación, salvo la exigencia de un informe por parte de la otrora Superintendencia de Compañías de Seguros, Sociedades Anónimas y Bolsas de Comercio (SCS). El artículo $4^{\circ}$ de dicha ley introdujo una serie de modificaciones a la Ley de la Renta, incluyéndose allí la alusión a la división de sociedades anónimas. Asimismo, el artículo 40 de dicha norma modificó la Ley $N^{0} 16.272$, sobre Timbres, Estampillas y Papel Sellado, sustituyendo el inciso segundo del $\mathrm{N}^{\circ} 24$ del artículo $1^{\circ}$ de dicha ley, por el siguiente: "En los casos de fusión, absorción o transformación de sociedades, o de división de sociedades anónimas, sólo se gravarán, en conformidad con el inciso precedente, los mayores capitales que se estatuyan o paguen en exceso, en relación con los capitales de las sociedades fusionadas, integradas, transformadas o divididas, siempre que estos últimos hayan pagado en su oportunidad los impuestos correspondientes" [la cursiva es nuestra]. La finalidad de dicha regulación habría sido establecer un principio de justicia tributaria que beneficiara a los accionistas de las sociedades que se dividieran, al no gravar con el impuesto global complementario y/o adicional las acciones que se recibieran como consecuencia de la división ${ }^{22}$.

Debido a la ausencia de normas sustantivas sobre la materia, la SCS debió colmar tal vacío, estableciendo las condiciones sobre las cuales operaría la división ${ }^{23}$.

Posteriormente, el Decreto № 1.995, de 1970, que modificó el Reglamento de Sociedades Anónimas de 1946, reemplazó el inciso $4^{\circ}$ del artículo 20 del

\footnotetext{
20 En donde estas operaciones son denominadas como corporate division o divisive reorganizations. EisenBerg (1969), p. 150; EBerhard (1999), p. 122.

21 Publicada en el Diario Oficial de 31 de diciembre de 1968.

22 Oficio № 2.048, de 14 de junio de 1989, de la SVS.

${ }^{23}$ Del reconocimiento tributario de la división de sociedades puede desprenderse que en la práctica societaria de la época se realizaban operaciones, al menos formalmente, denominadas división de sociedades, que ameritaron ser objeto de gravamen tributario. De esta forma, la división de sociedades, en tanto que operación encuadrable en la categoría de las modificaciones estructurales, comparte una de sus notas definitorias, que es su reconocimiento previo en sede tributaria, para sólo posteriormente ser consagrada en el ordenamiento mercantil. EMBID (1991), p. 16; EMBID (1991a), pp. 294-295; BALLester (1997), pp. 122-123; Gardeazábal del Río (2001), p. 2680. Tal fue asimismo la situación en los ordenamientos jurídicos en los que la escisión de sociedades tuvo sus orígenes aproximadamente a mediados del siglo XX (Francia e Italia), así como en otros ordenamientos latinoamericanos (México y Argentina). Al respecto, Duque (1978), pp. 127-130; Otaegui (1981), pp. 238-240; Villalón (1986), pp. 1173-1174; VASCONCELOS (1995), p. 472; ROJAS (2010), p. 802.
} 
citado Reglamento, estableciendo que sólo la Junta extraordinaria de accionistas, en la cual debería estar presente un Notario, era la instancia con atribuciones para tratar de la división de la sociedad, sin establecer mayores requisitos o exigencias sobre la materia.

Atendidos los vacíos indicados, la construcción administrativa de la división societaria efectuada por la SCS no sólo perduró hasta la entrada en vigencia de la LSA, que vino a consagrar legalmente la división, ya desde el Derecho Societario, sino que incluso transcendió a esta nueva normativa ${ }^{24}$.

En la actualidad, el texto de la LSA no es especialmente afortunado al definir la división de sociedades anónimas. El artículo 94 de la LSA alude a la división como un supuesto de distribución de patrimonio entre la sociedad dividida y una o más sociedades (división parcial), sin señalar en forma clara cómo opera dicha distribución. De esta manera, surgen dudas en cuanto a si dicha distribución opera en virtud de la técnica de la asignación de bienes pre-existentes, que es la postura actualmente en vigor, o en virtud de la técnica de la sucesión universal parcial, posición que propugnamos en este trabajo.

\section{b) Desarrollo jurisprudencial: conceptualización general de la división de sociedades}

Existiendo al menos el reconocimiento tributario de la división societaria, según se señala en el Of. № 2.048, de 14 de junio de 1989, de la SVS, su antecesora, la SCS, procedió a regular administrativamente las normas de la institución, adoptando una serie de criterios los cuales son compartidos actualmente por otros organismos reguladores ${ }^{25}$ y la Corte Suprema ${ }^{26}$.

\footnotetext{
${ }^{24}$ Sin perjuicio de la crítica realizable, la finalidad original de la interpretación parece clara y loable: suplir la falencia del ordenamiento jurídico chileno en cuanto a un verdadero régimen de neutralidad fiscal relativo a las operaciones de modificación estructural. Ello se efectuó sólo por medio de la Circular № 68, de 1996, del SIl, y después por medio de la Ley № 19.705, que modificó el artículo 64 del CT.

${ }^{25}$ Véanse entre otros, los Ofs. № 1.873, de 12 de junio de 1989, 2.734, de 23 de agosto de 1989, $\mathrm{N}^{\circ} 2.100$, de 26 de julio de 1996 y № 1.482, de 29 de marzo de 2004, todos ellos del SII. Por su parte, la Circular № 68, de 28 de noviembre de 1996, de dicho Servicio indica expresamente: "División de una sociedad.- Sobre este tipo de reorganización de sociedades de cualquier clase, cabe señalar que, teniendo presente un pronunciamiento de la Superintendencia de Valores y Seguros, este Servicio ha concluido que en el caso de división de una sociedad, la distribución que se hace del patrimonio de la sociedad que se divide corresponde a la asignación de cuotas de una universalidad jurídica y, consecuencialmente, no existe propiamente una transferencia o transmisión de bienes, sino que se trata de una especificación de derechos preexistentes los cuales, en virtud de la decisión societaria adoptada, quedan radicados en una entidad jurídica independiente. En consecuencia, el traspaso de los bienes que se efectúen con motivo de la división de una sociedad, no constituye propiamente un aporte puesto que no hay una enajenación (...)".

${ }^{26}$ El fallo de fecha 22 de noviembre de 2012, Rol No 8354-2011, en cuyos Considerandos $6^{\circ}$ y $7^{\circ}$ acoge lo señalado por la SVS en el citado Of. № 2.048, de 1989, y en el Of. № 2.734, de 1989, del SIl.
} 
Según señala el citado Oficio, en la división societaria, tanto antes de su reconocimiento por la LSA como bajo el imperio de ésta, habría una distribución patrimonial que corresponde necesariamente a una asignación de cuotas de la universalidad jurídica que representa el patrimonio de la sociedad que se divide, realizado por una decisión de los accionistas de la persona jurídica por simple reforma estatutaria, por lo que en esta operación no existiría propiamente una transferencia o transmisión de bienes, sino que habría una especificación de derechos preexistentes, los cuales, en virtud de la decisión societaria adoptada en la forma y por la mayoría que prescribe la ley, quedarían radicados en entidades jurídicas independientes, conformando ese mismo acuerdo el acto constitutivo de la nueva o nuevas sociedades que se crean $^{27}$. Así, en nuestro ordenamiento, la operatoria de la división de sociedades se ha encontrado tradicionalmente vinculada con las normas sobre partición de comunidades.

En cierto sentido, es posible ver en dicha construcción la influencia del Derecho norteamericano. En éste, la división de sociedades no posee una fisonomía particular, sino que su régimen jurídico se integra por el propio de cada uno de los actos que conforman la operación de división, sin mayores especialidades. Así, predominan las reglas sobre reparto de dividendos "in natura" en los casos de spin-off, de canjes de acciones en los supuestos de split-off, y de disolución en las split-up, sin perjuicio, asimismo, de la aplicación de las reglas generales contempladas para los supuestos de enajenación de todo o sustancialmente todo el activo ${ }^{28}$.

\section{c) La división de sociedades en la doctrina chilena}

La división de sociedades no ha sido objeto de estudios detallados por nuestra doctrina. Sin perjuicio de ello, cabe apreciar la existencia de diversas posturas en lo relativo a la naturaleza jurídica del traspaso de los bienes escindidos del patrimonio social original.

Así, en primer lugar, existe un sector ${ }^{29}$ que se limita a exponer la mera literalidad del texto normativo (LSA), sin abordar la naturaleza jurídica del traspaso patrimonial que se efectúa en la división.

Para otro sector ${ }^{30}$, siguiendo la posición de los organismos reguladores antes citados, el traspaso patrimonial que se efectúa con ocasión de una división

\footnotetext{
27 Peñailillo (2002), pp. 100-101.

28 Siegel (1966), pp. 536, 546-549; Eberhard (1999), pp. 122-123; Glover (2006), pp. 2-7, 2-15, 2-19; KRAAKMAN (2009), p. 211.

29 Es el caso de Villegas (1995), pp. 173-174; Morand (2004), pp. 144-145; Contreras (2005), pp. 451452; TORRES (2006), pp. 486-491.

30 Solovera (1996), p. 95; Hernández (2000), pp. 122-126; Bórquez (2002), p. 75; Baeza (2003), pp. 1325, 1341; Iglesias (2003), pp. 178-179; URENDA (2004), pp. 57-61; FAúNDEZ (2012), p. 280; VÁsQueZ (2013),
} 
societaria implica una especificación de derechos preexistentes, efectuada por medio de la distribución uti singuli de los bienes que conforman el patrimonio dividido, en la nueva entidad.

Finalmente, otro sector parece ver en la división de sociedades un supuesto de sucesión universal. Sin embargo, quienes sostienen esta posición no aportan mayores fundamentos al respecto ${ }^{31}$ o se basan precisamente en las consideraciones sobre las que la SVS y el SII interpretan la división de sociedades ${ }^{32}$, lo que parece cuando menos extraño, si se considera que en base a tales argumentos dichas entidades consideran que en la fusión hay un supuesto de traspaso uti singuli -y no in universum ius- de derechos preexistentes. Como hemos adelantado, creemos que la conceptualización más idónea es aquella que ve en la división de sociedades un supuesto de sucesión universal. A ella nos referiremos seguidamente.

\section{La sucesión universal como técnica jurídica al servicio del Derecho de sociedades}

\subsection{Concepto y utilidad en el ámbito del Derecho Privado Especial}

Desde una concepción amplia, la sucesión constituye una situación general (hecho jurídico) en cuya virtud una persona reemplaza a otra en la posición de sujeto activo o pasivo de relaciones jurídicas, vale decir, se trata de una transformación puramente subjetiva de una relación de derecho. Bajo dicha concepción es posible afirmar que el adquirente sucede al tradente en el dominio de la cosa objeto de tradición, que el comprador sucede al vendedor o

p. 702. En esta línea, PugA (2011), p. 634, rechaza expresamente la posibilidad de ver en la división societaria un supuesto de sucesión universal.

31 En este sentido parece opinar Puelma (2001), p. 219, al señalar que en la división “(...) se trata de que pueden crearse otras sociedades, que sucedan a la primera en todo o parte de su patrimonio" [la cursiva es nuestra]. LYON (2003), p. 208, afirma que "(...) lo que constituye la esencia de este acto jurídico, es que la nueva sociedad que surge de la división sucede a la antigua, esto es, recibe de ella parte de la organización jurídico-administrativa de su patrimonio [...] sucesión [la que] sólo se alcanza por medio de la división y por la fusión de sociedades". Por su parte, Sandoval (2010), pp. 391, 394, sostiene que en la división existe un traspaso patrimonial "en bloque", tomando la terminología utilizada por la legislación española de sociedades, en donde, primero doctrinal y ahora positivamente, se considera que la referencia al traspaso patrimonial "en bloque" implica que éste se efectúe por medio de la técnica de la sucesión universal (los artículos 69, 70 y 71 de la Ley $N^{\circ}$ 3/2009, de 3 de abril, sobre modificaciones estructurales de las sociedades mercantiles). Finalmente, Ríos (2008), p. 176, equipara la transferencia de patrimonios que hay en la división con la existente en la fusión.

32 Así, HERNÁNDEZ (2000), p. 126, quien pese a compartir la postura de los organismos reguladores, concluye que "(...) la asignación del patrimonio a la sociedad asignataria se efectúa como un todo y en bloque, en otras palabras, a título universal, independientemente de los bienes integrantes del patrimonio escindido". 
que el donatario sucede al donante ${ }^{33}$. Así definida, la sucesión se clasifica en sucesión por causa de muerte (mortis causa) y sucesión entre vivos (inter vivos), dependiendo, respectivamente, de si el hecho detonante de la sucesión es la muerte de una persona o un acto entre vivos; y en sucesión particular o universal, dependiendo de si su objeto es una o más relaciones jurídicas particular e individualmente consideradas, o una o más relaciones jurídicas, consideradas como un todo, respectivamente.

Atendiendo a la clasificación expuesta, se ha sostenido que la sucesión universal es una técnica que consiste en "(...) subentrar o colocarse una persona en el puesto de otra en una relación jurídica que permanece inalterada", produciéndose "(...) un cambio de la persona titular de la relación jurídica, pero ésta no se altera, es decir, no se extingue y se crea una nueva, sino que permanece con el cambio de la persona que subentra o se coloca como nuevo titular adquirente". Dicho cambio opera "(...) en bloque, en un solo acto, comprendiendo un conjunto de relaciones jurídicas transmisibles - derechos y obligaciones- desde el patrimonio de su titular [...] al de otro titular [...] como adquirente en bloque, sin necesidad de un acto transmisivo de cada una de las relaciones jurídicas singulares" ${ }^{34}$.

Esta institución sitúa sus orígenes en el Derecho romano, donde operaba sólo mortis causa, sin perjuicio de la existencia de supuestos inter vivos asimilables, pero no técnicamente idénticos a la sucesión mortis causa ${ }^{35}$. En Roma la transmisión operada en virtud de la muerte del causante no era estrictamente universal, ya que originalmente no abarcaba sus deudas, las cuales sólo en la época romana tardía fueron objeto de transmisión en virtud de la ficción de la continuidad de la persona del causante en su heredero, como consecuencia de la cual había un efecto de sustitución universal, ficción que se ha mantenido hasta nuestros días ${ }^{36}$.

En la actualidad, la técnica sucesoria ha sido objeto de utilización en el ámbito del Derecho Privado Especial, siendo de particular utilidad en el sector del

33 Savigny (1879), p. 153; Ruperto (1950), p. 123; Domínguez y Domínguez (1998), p. 127; Giovanni (2010), p. 2.

34 O'Callaghan (1999), p. 11. Asimismo, Savigny (1879), pp. 155-159; Betti (1943), pp. 28-32; Flume (2008), pp. 15-22.

35 Savigny (1879), pp. 152-160; Ruperto (1950), p. 125; Claussen (1995), p. 39; Soza (1999), p. 91, quien disiente de la corrección de aplicar el término sucesión al supuesto de fusión, por estimar que "(...) no puede hablarse realmente de una categoría de successio, que sólo parece aplicarse a las personas naturales; sí, en cambio, podríamos decir que se da una verdadera subrogación o colocación de una persona jurídica en la misma posición de la anterior, que ha desaparecido" (pp. 96-97).

${ }^{36}$ RafFray (2011), pp. 3-8. 
Derecho de Sociedades ${ }^{37}$. Sin embargo, éste ha modificado los presupuestos y los objetivos sobre los que descansa la sucesión universal común (mortis causa), para adecuarlos a las necesidades del tráfico. En efecto, la sucesión por causa de muerte, como dice su nombre, encuentra su razón de ser, su fundamento, su "causa", en la muerte de una persona. Sólo como resultado de dicho hecho se desencadenan las consecuencias sucesorias y opera el modo de adquirir "sucesión" (artículo 588 del CC). En cambio, la sucesión implementada en el ámbito del Derecho Privado Especial no tiene su fundamento en la muerte de una persona, sino que en un acto jurídico entre vivos, el cual ha sido tipificado por el legislador, a fin de reconocer sus efectos. De ahí que las disposiciones previstas en aquel sector no sean extensibles sin más a éste ${ }^{38}$.

Aplicando las referidas ideas al ámbito societario, es posible indicar que el principio de sucesión universal conlleva que tras el cumplimiento de las formalidades dispuestas por el ordenamiento, opera el traspaso automático de todos o al menos de una parte de los activos y pasivos de una sociedad, a otra u otras sociedades nuevas o preexistentes ${ }^{39}$. Dicho traspaso opera como un todo, sin que la operación pueda considerarse, en estricto rigor, ni como una transferencia ni como una transmisión ${ }^{40}$.

La importancia de la aplicación de esta técnica en el ámbito del tráfico comercial estriba en que "(...) el principio de la sucesión universal ayuda eficazmente al traspaso patrimonial de una a otra sociedad al permitir que los distintos bienes, derechos y obligaciones integrantes del patrimonio de la sociedad disuelta se transmitan uno actu. Si no se aceptase este principio, habría que adoptar el lento y dispendioso procedimiento de descomponer la transmisión patrimonial en los singulares negocios jurídicos idóneos para la transmisión de los distintos elementos integrantes del patrimonio (la compraventa, la cesión de créditos, el endoso, etc.), y con ello las posibilidades prácticas de la fusión

\footnotetext{
${ }^{37}$ Flume (2008), p. 1. Críticamente, sobre el uso de dicha técnica del Derecho Común en materia de modificaciones estructurales, GONZÁLEZ-MENESES (2010). Sin embargo, la técnica sucesoria no es exclusiva de dicho sector del Derecho, ni siquiera del Derecho Privado, por cuanto ella, con sus correspondientes diferencias, ha sido utilizada en otros sectores normativos, como el Derecho Internacional Público (en materia de sucesión de Estados) o el Derecho Administrativo (en materia de fusión de servicios públicos). En este sentido, Santagata (1964), p. 94.

38 Gardeazábal del Rio y Martínez (1991), p. 272; Sequeira (1993), p. 96; Schmidt (1995), p. 200; Trías (2001), p. 74; Camacho De Los Ríos (2004), p. 53; Conde (2004), pp. 371-372; Garrido de Palma (2012), p. 147.

39 Dauner-Lieb (2009), p. 11.

40 Contés y Pérez (2008), p. 59. Por ello, parece más adecuado hacer alusión al "traspaso", término genérico que no implica adoptar una posición en relación a si la fusión es una operación inter vivos o mortis causa. Al respecto, GuZMán (2006).
} 
quedarían reducidas a cero" ${ }^{\prime 4}$. De esta forma se cumple con las exigencias de simplicidad y estandarización propias de las operaciones de reestructuración societaria ${ }^{42}$, pudiendo llegar a afirmarse que el principio de sucesión universal patrimonial constituye un elemento fundamental del Derecho de fusiones y escisiones ${ }^{43}$.

\subsection{Operatoria}

Con carácter general, la doctrina destaca que la sucesión opera:

(i) in universum ius, es decir, respecto de una universalidad representada por la totalidad de un patrimonio (sucesión universal total) o por una porción del mismo (sucesión universal parcial) ${ }^{44}$. El traspaso operado abarca un patrimonio, como un todo, per universitatem, o solo una o más porciones del mismo, aunque también como universalidad ${ }^{45}$, considerando en ambos casos sus elementos activos y pasivos, en tanto que integrantes de la idea de patrimonio, sin perjuicio de la existencia de supuestos en los que la operatoria de la sucesión universal podría verse limitada, como es el caso de los negocios jurídicos intuitu personae ${ }^{46}$;

(ii) uno actu, es decir, por medio de un único acto, que viene a constituir la causa de la sucesión; distinguiéndose así de los supuestos de sucesión singular, en los que opera un traspaso individual de los bienes que integran un patrimonio, singulis actibus, de acuerdo a las particulares normas de circulación de cada uno de ellos, según la naturaleza de los mismos, aspecto que recibe la denominación de principio de especialidad circulatoria ${ }^{47}$. Ello implica que la

${ }^{41}$ Garrigues Y Uría (1976), p. 749.

${ }^{42}$ Couret (2009), p. 376.

43 Albortchire (2005), p. 19.

${ }^{44}$ Sobre esta categoría sucesoria, ya SAVIGNY (1879), pp. 155-156. Para el ordenamiento alemán, EbeRhard (1999), pp. 58-59. Para Italia, Mantovani (2008), pp. 26-32. Para España, Embid (1991), nota al pie № 60; CONDE (2004) pp.384-394. En Suiza, véase el fallo de 31 de enero de 2006 del Bundesgericht (4C.385/2005), en el que se afirma que la sucesión universal parcial es cualitativamente un supuesto de sucesión universal, si bien limitado cuantitativamente a ciertos elementos. Así, el carácter "parcial" se refiere únicamente al alcance de la sucesión universal, pero no a sus efectos jurídicos. Asimismo, Solari (2004), p. 187; Garrido de Palma (2012), p. 147.

45 Claussen (1995), p. 123; Conde (2004), p. 385; Raffray (2011), p. 151.

46 Al respecto Marty (1999), p. 72; Couret (2009), pp. 379-384; Burg y Ory (2012), pp. 79-80. En nuestra doctrina, Ríos (2008), p. 176.

${ }_{47}$ Respecto de este principio se sostiene que el mismo significa que la propiedad puede estar constituida sólo sobre objetos precisos y bien definidos, y que por consiguiente, una transferencia de propiedad sólo es posible respecto de tales objetos. Este principio persigue un fin de transparencia y de publicidad en las relaciones de propiedad. Él presume que una transferencia de propiedad puede efectuarse sólo 
operación se perfecciona con el cumplimiento de las especiales formalidades previstas al efecto y no de acuerdo a las normas generales de circulación de cada clase de bienes. La doctrina ha calificado esta operatoria como efecto facilitador o Erleichterungseffekt ${ }^{48}$, dado que busca evitar tener que cumplir con variadas y engorrosas actuaciones tendientes a lograr el traspaso en la titularidad de cada bien que integra el patrimonio traspasado, reemplazándolo por un procedimiento unificado, cuyo objeto es facilitar la circulación de los patrimonios objeto de la operación de que se trate. La aludida simplificación circulatoria implica asimismo omitir las normas de tutela previstas para el traspaso de los bienes particulares (esencialmente, lo relativo a la necesidad de contar con el consentimiento de los acreedores de la sociedad que se extingue), consecuencias todas éstas calificadas usualmente por la doctrina como excepcionales ${ }^{49}$;

(iii) voluntaria, por cuanto dicho acto depende del mero arbitrio de la o las sociedades que participan en la operación, y que, en tanto tal, puede o no traer como consecuencia la extinción de una o más sociedades que participan en la operación;

(iv) inter vivos, vale decir, entre vivos, asumiendo sólo a efectos clasificatorios la asimilación entre "vida" y existencia, propia de las personas jurídicas, para diferenciarla así de la sucesión mortis causa ${ }^{50}$. Esto quiere decir que la operación de que se trate se efectúa entre dos entidades con existencia jurídica, no operando la desaparición de algunos de dichos entes como presupuesto para la operatoria de la técnica sucesoria ${ }^{51} ;$,

sobre un objeto muy preciso y en virtud de un acto de disposición operado especialmente para este objeto. EBerhard (1999), p. 57.

${ }^{48}$ Flume (2008), pp. 5-6.

${ }^{49}$ En general sobre estos aspectos, Garrigues (1949), pp. 1290-1293; Motos (1953), pp. 52-56; Santagata (1964), pp. 104-110; Pérez (1970), p. 60; Cámara (1985), p. 302; Gardeazábal Del Rio y Martínez (1991), pp. 271-272; Gómez (1991), pp. 47-49; Sequeira (1993), pp. 95-96; Stengel (1995), p. 91; Solari (1996), p. 80; Marty (1999), pp. 71-72; Conde (2004), pp. 65-68, 368-374; Hegemann (2007), p. 21; Alonso Ledesma (2009), p. 485; Alonso Ureba (2009), pp. 639-640; Couret (2009), p. 374; Dauner-Lieb (2009), pp. 10-11; Kessler y KüHnberger (2009), p. 7; González-Meneses (2010); Kallmeyer et al. (2010), p. 3.

${ }^{50}$ En este sentido, calificando a la sucesión universal en la fusión como un supuesto de naturaleza sui generis, por cuanto tiene lugar entre personas jurídicas y del que no son predicables más caracteres que los que se derivan de la regulación que de ella se hace en cada ordenamiento, Gómez (1991), p. 52. Asimismo, Pérez Milla (1996), p. 183.

51 Ruperto (1950), p. 138. Esto se explica claramente por el Abogado General TizzAno, en sus Conclusiones presentadas en el Asunto Sevic Systems AG (Asunto C-411/03), conocido el año 2005 por el Tribunal de Justicia de las Comunidades Europeas en materia de libertad de establecimiento. En ellas señala lo siguiente: "26. (...) durante todo el período que precede a la fusión y hasta la inscripción registral de la misma, ambas sociedades existen y actúan como personas jurídicas plenamente capaces de negociar y acordar la fusión. La extinción de uno de los dos sujetos de derecho sólo tiene lugar al perfeccionarse la fusión y, en particular, al precederse a la inscripción registral de la misma, pero no 
(v) ex lege, es decir, por virtud de la ley y sólo si así se contempla en ella ${ }^{52}$, lo que implica excluir el juego de la autonomía privada en cuanto a reconocer este particular efecto si la ley no lo ha previsto para la operación de que se trate $^{53}$, consideradas las excepcionales consecuencias jurídicas que conlleva esta sucesión universal, las cuales a su vez impedirían su extensión analógica.

\title{
2.3. Extensión
}

\author{
Atendida la configuración "tipológica" de las operaciones de modificación \\ estructural ${ }^{54}$, la técnica de la sucesión universal no concurre en todas las ope-
}

antes, y buena prueba de ello es el hecho de que, en el caso de que la operación no llegue a perfeccionarse, la sociedad que habría debido ser absorbida continuará existiendo como persona jurídica autónoma" [la cursiva es nuestra].

52 Así para las fusiones, Ballester (1997), pp. 128-129; LARGo (1997), p. 169; GeVurtz (2000), pp. 645, 655; Gardeazábal Del Rio (2001), pp. 2687-2688; Bainbridge (2003), p. 155; Conde (2004), p. 68; Oesterle (2005), p. 226; HeGemann (2007), p.21; Couret (2009), p. 374. En relación a la escisión, Girón (1976), p. 370; EMBiD (1991), p. 31; Alonso Ledesma (2009), p. 485. En relación a la cesión global de activos y pasivos, Conde (2004), pp. 461-466; Alonso Ureba (2009), pp. 639-640. En este mismo sentido, en materia de fusiones internacionales, Bron (2005), p. 16; Beutel (2008), p. 14.

53 Santagata (1964) pp. 355-358. Ya lo reconocía así Savigny (1879), p. 157.

${ }^{54}$ En el campo de la aplicación del Derecho es posible distinguir entre "conceptos" (Begriff) y "tipos" (Typus), considerados como formas de concreción de lo general e incardinados, por tanto, en el constante proceso lógico de "concretar lo abstracto", de particular relevancia en el ámbito jurídico, por cuanto implica aspirar a acercar dicha ciencia a la realidad. Como ha destacado la doctrina, el método de acercamiento tradicional de lo general a lo particular ha sido a través de la definición conceptual por abstracción sustractiva. Éste implica la definición de un género o especie por medio de la eliminación de sus particularidades y su posterior identificación por remisión a lo que les es común. Con Hegel se abrió paso una nueva corriente, primero sociológica y luego jurídica, que abogó por un mayor acercamiento de lo abstracto a lo real, proceso en el que ocupó y ocupa un lugar esencial la idea de tipo. Éste ha sido definido como una "(...) técnica de conocimiento que sirve para penetrar la significación, el sentido último de los fenómenos individuales del mundo de la cultura, y en función de ello determinar el sentido y alcance de sus diferentes partes o elementos. En el derecho la "unidad de sentido" de los institutos resulta aprehensible mediante el "tipo", que nos permite comprender con plenitud de sentido la posición y las funciones de los diferentes elementos del instituto" (Montoro (1982), p. 53). La diferencia entre concepto y tipo estriba en que mientras aquél implica una menor valoración subjetiva de la norma, ya que todos los elementos distintivos del mismo aparecen expresados de forma clara en ella, de manera que existe, al menos en teoría, una mera subsunción y por ende, ausencia valorativa, el tipo conlleva la existencia de notas distintivas que no precisan estar todas necesariamente presentes en cada caso, sino que las mismas pueden presentarse con diversa intensidad y unión, es decir, son graduables. Así, la integración en un tipo, a diferencia de lo que ocurre con los conceptos, sí es un procedimiento orientado a valores, procedimiento consistente con la consideración del sistema como una "(...) aprehensión racional de la coherencia de un entramado jurídico de valoraciones" (CANARIS (1998), p. 52). Pese a que lo indicado pareciera significar la existencia de una suerte de incompatibilidad entre conceptos y tipos, lo cierto es que ambos se encuentran estrechamente unidos, ya que generalmente tras los conceptos fijados legalmente es posible apreciar igualmente la existencia de tipos, desde que el concepto legal puede en ocasiones encontrarse definido por medio de notas distintivas, de las cuales al menos una puede ser abierta como los tipos; o a la inversa, un 
raciones que conforman dicha categoría, lo cual, en todo caso, dependerá del ordenamiento positivo en cuestión. Por lo pronto cabe dejar destacado que la misma concurre normalmente en la fusión, en la escisión y en las transferencias de activos y pasivos (denominadas en España, cesiones globales de activos y pasivos $^{55}$, en Francia, apport partiel $d^{\prime}{ }^{\prime}{ }^{2}{ }^{5} f^{56}$, y en Alemania, Vermögensübertragung ${ }^{57}$ ), y no concurre en la transformación societaria, en la que opera una mutación del tipo societario con mantención de la personalidad jurídica (identidad del titular) $^{58}$.

Ahora bien, basándose en la doctrina alemana, un sector estima que la técnica de la sucesión universal también se presenta en la transformación, convirtiéndose de esta manera en un elemento definitorio y transversal en la delimitación de las operaciones que integran la categoría de las modificaciones estructurales. Para este sector, las adecuaciones que en sede mercantil se han efectuado a la institución de la sucesión universal han llevado a distinguir diversos medios de

tipo puede aproximarse a un concepto mediante la fijación de algunas notas distintivas irrenunciables, acompañadas de otras que son prescindibles. LARENZ (2001), pp. 205-215, 451-452; ENGISCH (2004), pp. 358-359; Vallet De Goytisolo (2004), p. 490; Gil (2004), p. 49. En Chile, sobre la diferencia entre concepto y tipo, QUINTANA (2001), pp. 186-195.

${ }^{55}$ Véase el artículo 81 de la española Ley № 3/2009, de 3 de abril, sobre modificaciones estructurales de las sociedades mercantiles, que al tratar de la cesión global de activo y pasivo permite que una sociedad transmita en bloque todo su patrimonio a otra u otras por sucesión universal a cambio de una contraprestación que no podrá consistir en acciones, participaciones o cuotas del cesionario.

${ }^{56} \mathrm{Al}$ respecto, la Corte de Casación francesa ha resuelto que "(...) sauf dérogation expresse prévue par les parties, communauté ou confusion d'intérêts ou fraude, l'apport partiel d'actif emporte, lorsqu'il est placé sous le régime des scissions, transmission universelle de la société apporteuse à la société bénéficiaire de tous les droits, biens et obligations dépendant de la branche d'activité qui fait l'objet de l'apport". Sala Comercial, fallo de fecha 22 de febrero de 2005.

57 Véase el $\$ 174$ de la UmwG, que señala “(1) Ein Rechtsträger (übertragender Rechtsträger) kann unter Auflösung ohne Abwicklung sein Vermögen als Ganzes auf einen anderen bestehenden Rechtsträger (übernehmender Rechtsträger) gegen Gewährung einer Gegenleistung an die Anteilsinhaber des übertragenden Rechtsträgers, die nicht in Anteilen oder Mitgliedschaften besteht, übertragen (Vollübertragung). (2) Ein Rechtsträger (übertragender Rechtsträger) kann 1. unter Auflösung ohne Abwicklung sein Vermögen aufspalten durch gleichzeitige Übertragung der Vermögensteile jeweils als Gesamtheit auf andere bestehende Rechtsträger, 2. von seinem Vermögen einen Teil oder mehrere Teile abspalten durch Übertragung dieses Teils oder dieser Teile jeweils als Gesamtheit auf einen oder mehrere bestehende Rechtsträger oder 3. aus seinem Vermögen einen Teil oder mehrere Teile ausgliedern durch Übertragung dieses Teils oder dieser Teile jeweils als Gesamtheit auf einen oder mehrere bestehende Rechtsträger, gegen Gewährung der in Absatz 1 bezeichneten Gegenleistung in den Fällen der Nummer 1 oder 2 an die Anteilsinhaber des übertragenden Rechtsträgers, im Falle der Nummer 3 an den übertragenden Rechtsträger (Teilübertragung)" [la cursiva es nuestra]. En las referencias a la transferencia patrimonial als Ganzes y als Gesamheit la doctrina germana fundamenta el traspaso en virtud del principio de sucesión universal total y parcial. Flume (2008), p. 84.

${ }^{58}$ Cfr. el artículo 96 de la LSA. Asimismo, véase SСнмiDt (1995), p. 214; sobre el principio de identidad en la transformación, Claussen (1995), pp. 120-121. 
concreción de dicha institución, según cuál sea la operación de que se trate. Así, la sucesión universal opera de diversas formas, todas las cuales integran el género sucesión universal y comparten, por ende, la misma naturaleza: en la fusión hay un traspaso de un bloque patrimonial, in integrum, a otro titular; en la división, el referido traspaso es parcial; y en la transformación, el traspaso se opera por medio del cambio del tipo social del titular del patrimonio ${ }^{59}$. En virtud de lo anterior se sostiene que los supuestos de fusión y transformación no significan otra cosa que el paso de universalidades patrimoniales al titular de otra empresa o al titular empresarial en otra forma jurídica ${ }^{60}$.

\subsection{La sucesión universal en Chile}

En Chile, el Código Civil recoge expresamente la sucesión por causa de muerte y la califica como modo de adquirir (artículo 588 del CC), circunstancia la cual ha operado como importante lastre doctrinal. En efecto, en lo tocante a la técnica del traspaso patrimonial total o parcial, in universum ius y uno $a c t u$, por medio de la sucesión universal "inter vivos" ${ }^{61}$, en particular, entre sociedades, es posible constatar la existencia de una fuerte reticencia por parte de la doctrina a aceptar supuestos de sucesión universal que no tengan como presupuesto fáctico la muerte de una persona natural ${ }^{62}$, siendo común encontrar afirmaciones en cuanto a que la sucesión por causa de muerte es el único modo de adquirir a título universal que existe ${ }^{63}$. Por ello se ha señalado con

${ }^{59}$ CONDE (2004), pp. 375-378, y la doctrina alemana citada en p. 378 nota al pie № 23. En Alemania la transformación transmisiva (transformación por disolución y creación de nueva sociedad) fue la regla general hasta la actual UmwG. De ahí que pueda entenderse el motivo de la inclusión, aún hoy día y al menos por un sector, de la transformación en el elenco de operaciones de sucesión universal. SCHMIDT (1995), pp. 211-213.

${ }^{60}$ SCHMidt (1995), p. 208.

${ }^{61}$ Calificativo que se usa sólo a fin de diferenciar a este supuesto sucesorio del mortis causa, ya que en estricto rigor, en el ordenamiento chileno no cabe referirse a las sociedades como entes "vivos", por cuanto el mismo califica expresamente a las personas jurídicas como una ficción (cfr. el artículo 545 del Código Civil).

${ }^{62}$ El artículo 951 inciso $2^{\circ}$ del Código Civil señala en relación a la sucesión que "El título es universal cuando se sucede al difunto..." [la cursiva es nuestra].

${ }^{63}$ Así, Olavarría (2004), p. 53. Enfático es, asimismo, Bustamante (1998), p. 373, al afirmar que “(...) [e] ntre nosotros, no existe más sucesión a título universal que la por causa de muerte, y toda otra sucesión, por acto entre vivos o por causa de muerte, es a título singular. En este punto, conviene precisar que sucesión universal significa, como dice Santoro Pasarelli, sucesión per universitatem y se da sólo en la sucesión de la herencia, porque solamente ésta constituye una universalidad, o sea, una pluralidad unificada de relaciones para el supuesto preciso de la sucesión: las demás universalidades son tales para otros efectos" [la cursiva es nuestra]. Por su parte, Domínguez y Domínguez (1998), p. 131, señalan que "(...) [e]s principio de nuestro derecho que la sucesión entre vivos es siempre a título particular, pues comprende necesariamente ciertas y determinadas relaciones jurídicas del autor. Así, el art.1811 
acierto que en esta materia "(...) Ilama la atención el hecho de que los civilistas liguen el concepto de la sucesión universal con una imagen jurídica basada en un paradigma: el ejemplo de la sucesión hereditaria" ${ }^{\prime \prime 4}$, apreciación que parece plenamente extrapolable a nuestra realidad jurídica. De ahí que cualquier intento tendiente a justificar la existencia de supuestos de sucesión universal inter vivos total o parcial -de carácter voluntario, en el que la extinción de la persona no es un presupuesto de hecho de la operatoria de la técnica, sino que más bien, cuando se da, un efecto de la misma-, así como las particularísimas consecuencias que de ello se derivan, se encontrará normalmente con los obstáculos que, a tales efectos, constituye la doctrina civilista, la cual se sujeta de algunos dogmas que a la luz del ordenamiento vigente han de replantearse o cuando menos matizarse ${ }^{65}$.

El primer dogma que debe cuestionarse es aquél que ve en la sucesión por causa de muerte el único supuesto legal de sucesión universal. Al día de hoy, tanto en los ordenamientos comparados como en el Derecho chileno, es posible encontrar otros supuestos normativos que se valen de la técnica sucesoria universal, basándose en razones y estructurándose de maneras diversas a

declara nula "la venta de todos los bienes presentes o futuros o de unos y otros, ya se venda el total o una cuota", nulidad que es absoluta. Por el art. 2056 se "prohíbe toda sociedad a título universal, sea de bienes presentes y venideros, o de unos u otros", disposición que se ha entendido siempre como la consagración positiva del principio de que nos venimos ocupando, esto es, que la sucesión en el patrimonio o de una cuota [o] parte del mismo, no es admisible por acto entre vivos, cualquiera que sea la forma que ella adopta". Y tales consideraciones se pueden apreciar también en la doctrina extranjera. Así, se ha sostenido que "La successione, inoltre, è particolare, o a titolo particolare, e universale, o a titolo universale. [...] Quanto alla seconda specie, essa non si verifica mai per atto inter vivos, ma solo mortis causa, sebbene non manchi chi ha sostenuto che va eccettuata la fusione tra società (regolata dagli artt. 2501 ss. cod. civ.), che determina una situazione analoga alla successione universale. Si è obbiettato, tuttavia, che l'atto di fusione non presuppone, ma determina, l'estinzione dei soggetti, con la conseguenza che si ha conferma del dato, secondo cui la sola successione universale è quella mortis causa. Essa, dunque, comporta la trasmissione del patrimonio di un soggetto, che muore, a un altro, chiamato a raccoglierlo. In virtù dell'acquisto di un'eredità, si ha il passaggio dei rapporti patrimoniali nella loro globalità". GiovanNi (2010), p. 3.

${ }^{64}$ SCHMidT (1995), p. 200, quien califica a tal figura como “(...) una solución provisional explicable históricamente (y superable)", p. 213, sosteniendo además que "(...) [l]a figura de la transformación transmisiva es innecesariamente complicada. Tiene su explicación, en parte, en el ya mencionado carácter pionero del Derecho de fusiones, pero también en un doctrinarismo obstinado, que se resiste frente a la idea de admitir la "identidad" de titulares jurídicos con diferente estructura", SCHMIDT (1995), p. 214. También dan cuenta de dicha dificultad en Francia, MARTY (1999), p. 73; RAFFRAY (2011), p. 25.

${ }^{65}$ Nos referimos no sólo al dogma de la exclusividad de la sucesión universal mortis causa sino que también al de la inscripción registral inmobiliaria como única forma de tradición de los inmuebles y al del patrimonio como atributo de la personalidad, con todos sus derivados (en especial, su indivisibilidad e incomerciabilidad). 
las propias de la sucesión por causa de muerte. La fusión de sociedades es el ejemplo más claro de ello ${ }^{66}$.

Junto a lo anterior, debe considerarse que la técnica de la sucesión universal inter vivos entre sociedades no es ajena al modelo general sucesorio contemplado en el ordenamiento jurídico chileno en sede de sucesión mortis causa, desde que, al igual que éste, se configura como un modelo unitario y personalista de corte Savignyano ${ }^{67}$, sin perjuicio de las especialidades que le son inherentes ${ }^{68}$.

Y por otra parte, la sucesión universal en materia societaria ha sido objeto de un paulatino reconocimiento doctrinal y parcialmente normativo, si bien con una limitada comprensión de sus consecuencias jurídicas reales. Desde la perspectiva doctrinal, el reconocimiento se efectuó originalmente en forma previa a la dictación de la LSA, tanto en materia de transformación como de fusión de sociedades, y positivamente sólo en relación a esta última operación -al menos en forma indiscutible-, tras la dictación de dicha ley.

Seguidamente se analizarán los efectos de la sucesión universal en el ordenamiento chileno común y societario y posteriormente se abordará la incorporación de la técnica sucesoria en sede de división societaria.

66 Ruperto (1950) pp.125, 135-143. Más recientemente, la Corte de Casación italiana en sentencia de 24 de junio de 2005 ( N 13695) ha señalado en forma clara que "La fusione di una società per incorporazione in un'altra, come noto [...], determina automaticamente l'estinzione della società assoggettata a fusione e il subingresso nei rapporti a essa relativi, per successione a titolo universale, della società incorporante". Véase el comentario del fallo efectuado por GALIMI (2005) p.58.

${ }^{67}$ Que se aprecia esencialmente en tres aspectos, a saber: (i) en su carácter subjetivo, es decir, vinculación a la persona del difunto; (ii) en el traspaso de relaciones jurídicas en vez de su extinción y; (iii) en la utilización de conexiones personales en sede de conflictos de leyes -nacionalidad o domicilio-. Pérez Milla (1996), pp. 181-187. En el ordenamiento chileno, tales aspectos pueden verse claramente en el artículo 951 del Código Civil, que reza "Se sucede a una persona difunta a título universal o a título singular" [la cursiva es nuestra]; en el artículo 1097, al disponer que "Los asignatarios a título universal, con cualesquiera palabras que se les llame, y aunque en el testamento se les califique de legatarios, son herederos: representan la persona del testador para sucederle en todos sus derechos y obligaciones transmisibles" [la cursiva es nuestra], consagrando así el principio de continuación del causante por sus herederos; y en el artículo 955 del mismo Código, que indica que "La sucesión en los bienes de una persona se abre al momento de su muerte en su último domicilio; salvos los casos expresamente exceptuados" [la cursiva es nuestra].

68 En contraposición a los modelos fragmentarios de naturaleza objetiva -esencialmente seguidos en el Common Law-, en los que el énfasis se pone esencialmente en el aspecto traslativo de bienes de la sucesión, separándose de consideraciones relativas a la persona y a la sustitución de una por otra que importa la sucesión en los modelos unitarios. Sobre los diversos modelos sucesorios existentes a nivel comparado, Pérez Milla (1996), pp. 181-187, y con mayor profundidad, Castellanos (2003). Sobre el acercamiento hacia los modelos unitarios, véase el reporte explicatorio con que se acompañó el Convenio sobre la ley aplicable a las sucesiones por causa de muerte, hecho en La Haya, el 1 de agosto de 1989, elaborado por Waters (1990), p. 535. Aunque el referido Convenio ha tenido escasa aceptación: fue suscrito por 4 Estados y ratificado sólo por uno. 


\subsection{Operatoria general de la técnica sucesoria}

Como se estudió previamente, esta técnica se caracteriza por los siguientes aspectos: opera in universum ius, uno actu, es de naturaleza voluntaria, inter vivos, y ex lege.

\section{a) Traspaso in universum ius}

En virtud de la sucesión universal se efectúa el traspaso íntegro del patrimonio de las sociedades que se extinguen como consecuencia de la operación, es decir, como un todo, y por tanto, del conjunto de bienes, derechos y obligaciones que conforman el patrimonio de las citadas sociedades. A la referida regla general podrán oponerse excepciones, en la medida que sea la propia ley la que contemple supuestos que se excluyen de la operatoria de la técnica sucesoria.

$\mathrm{Al}$ respecto es interesante destacar lo resuelto por la Corte de Apelaciones de Talca, en su fallo de fecha 1 de junio de 2011 (Roles No 627 y 628-2010, acumulados), en relación a la sucesión universal en la fusión. Señala el referido fallo que:

"(...) no existe en las fusiones pagos de las deudas, división ni distribución de bienes ni asignación de obligaciones que conlleva el patrimonio que se adquiere que pertenecía a la sociedad disuelta, ya que la totalidad de sus elementos, como un todo, se radican en el patrimonio la sociedad absorbente o continuadora. Ésta es la principal característica y a la vez efecto de las fusiones, vale decir, la "transmisión" a título universal de los patrimonios de las sociedades disueltas al patrimonio de las sociedades absorbentes, en toda su significancia, sin distinción y sin excepción. Si bien es cierto que el efecto de "transmisión" es propio de las sucesiones por causa de muerte, en este caso ésta debemos entenderla en los mismos términos en que el legislador la entiende en el pago con subrogación prevenido en el artículo 1.608 del Código Civil, pero en un contexto más amplio, pues se transmiten todos los derechos y las obligaciones, principales y accesorias, sin limitación..." (Considerando 8);

"[...] La sociedad continuadora o absorbente reemplaza por el solo ministerio de la Ley a las sociedades que se extinguen o disuelven como consecuencia de la fusión, en todas sus relaciones jurídicas, tanto activas como pasivas. Por tanto, así respecto de los créditos y derechos reales que se radican en el patrimonio de la absorbente de los que haya sido titular la absorbida o fusionada, como hipotecas y prendas activas, podrán ser ejercidas por la fusionante. De esta forma se produce una verdadera subrogación por el solo ministerio de la Ley, al mantenerse el crédito mismo en la fusionante cambiando sólo el titular de la relación jurídica. De la misma manera se radican en la continuadora todos aquellos accesorios de orden patrimonial que se relacionan con los activos adquiridos, como los intereses y reajustes de los créditos. Pero también se produce una sucesión de las obligaciones de que haya sido deudor la fusionada, como asimismo de todos los accesorios que emanen de estas obligaciones...". (Considerando 9). 
Sin embargo, el referido traspaso in universum ius también concurre cuando el objeto de dicho traspaso es una porción patrimonial conformada por un conjunto de relaciones activas y pasivas, las cuales pasan a radicarse bajo otro titular, sucediendo este nuevo titular al antiguo. El ejemplo más claro de esta posibilidad se encuentra en materia sucesoria. En efecto, el artículo 951 inciso $2^{\circ}$ del Código Civil señala que "El título es universal cuando se sucede al difunto en todos sus bienes, derechos y obligaciones transmisibles, o en una cuota de ellos, como la mitad, tercio o quinto" [la cursiva es nuestra]. Como se desprende de la disposición transcrita, incluso en los supuestos en los que se transmite una cuota de los bienes hereditarios cabe que el título de transmisión sea universal.

\section{b) Traspaso uno actu}

Tanto en los supuestos de sucesión universal total como parcial, el traspaso patrimonial opera uno actu, es decir, en virtud de un único acto, sin que por tanto sea necesario cumplir con las formalidades específicas que contempla el Derecho Común para la circulación de los diferentes bienes y derechos. Así, todas las reglas comunes que regulan el traspaso del dominio y otros derechos reales respecto de los bienes muebles (artículo 684 del Código Civil), inmuebles (artículo 686 del Código Civil), derechos (artículos 698, 699 y artículos 1901 y ss. del Código Civil ${ }^{69}$ ) y obligaciones (artículos 1628 y ss. del Código Civil), ceden ante las especiales formalidades previstas para la operación en cuya virtud opera la sucesión universal.

Precisamente, en lo expuesto se aprecia la importancia del carácter ex lege de la institución de la sucesión universal, ya que implica desplazar tales solemnidades por las formalidades contempladas para la perfección de las operaciones societarias, consistentes en la escrituración pública del acto societario en cuestión, y su posterior inscripción en el Registro de Comercio del respectivo Conservador de Bienes Raíces. Por tanto, es en virtud del cumplimiento de estas formalidades que se despliegan los efectos sucesorios respectivos. En esta línea, un fallo emitido por la Corte de Apelaciones de Santiago, de fecha 23 de marzo de 1994, en la causa caratulada "Banco Bhif con Sergio Fernández Rojas", sostuvo que:

"(...) conforme a lo dispuesto por el artículo 99 de la LSA, como consecuencia de la fusión de sociedades anónimas la que resulta subsistente sucede, a las absorbidas, en todos sus derechos y obligaciones, una vez cumplidas las formalidades

${ }^{69}$ Es interesante resaltar además cómo el artículo 1908 del Código Civil reconoce expresamente que las normas de los artículos 1901 a 1907 del Código, sobre cesión de créditos personales, no se aplican a las letras de cambio, pagarés a la orden, acciones al portador y otras especies de transmisión que se rigen por el Código de Comercio o por leyes especiales. 
legales. [...] [P]or lo expuesto en el considerando anterior, no ha sido necesaria la anotación al margen de la hipoteca en que el Banco funda su acción, o una nueva inscripción de ella, para que el Banco BHIF, pasare a ser titular de dicho derecho, ya que tal anotación sólo cumpliría el rol de actualizar la historia del derecho real de hipoteca...".

Y siguiendo la línea de dicha sentencia, el antes citado fallo de la Corte de Apelaciones de Talca señaló que:

"(...) Es propio de las fusiones que los bienes comprendidos en los patrimonios fusionados, conserven su calidad y naturaleza jurídica que mantenían en la sociedad absorbida. También que conserven como fecha de adquisición de los mismos la fecha en que fueron adquiridos por la sociedad fusionada disuelta. Lo anterior es consecuencia y prueba concluyente, de que en las fusiones no existe traslación o transferencia de dominios de los bienes que se adquieren como consecuencia de la transmisión de los patrimonios. En razón de este efecto es que no se requiere una nueva inscripción de los bienes inmuebles que se adquieren por la fusión, a lo más procederá una anotación marginal, lo mismo respecto de las hipotecas que graven a dichos bienes. Los mismos efectos se deben observar respecto de los pasivos u obligaciones, principales y accesorios, en cuanto a su calidad y naturaleza jurídica que mantenían en la sociedad disuelta. Respecto de las obligaciones que se suceden por la absorbente no se extinguen por la fusión, de ser así este modo de extinguir obligaciones debería encontrarse previsto como tal en el artículo 1.567 del Código Civil, o en alguna ley especial, lo que no sucede..." (Considerando 10).

\section{c) Traspaso voluntario e inter vivos}

Tales aspectos se desprenden claramente del tenor de las normas que regulan las operaciones que utilizan la técnica de la sucesión universal. Así, tanto la división como la fusión de sociedades son actos societarios cuya adopción se encuentra radicada en la Junta Extraordinaria de socios, ex artículo 57 de la LSA, y no encuentran su causa en la extinción de persona alguna, sino que en un acto inter vivos: en efecto, en la fusión sólo con la perfección de la operación opera la extinción inherente a ella, no antes; en la división, en nuestro ordenamiento jurídico, no hay extinción.

\section{d) Traspaso ex lege}

La correcta operatoria de la sucesión universal demanda su reconocimiento normativo, atendidas sus particulares consecuencias, siendo la ley la única fuente de éstas. De esta manera, es la ley la causa de la sucesión universal. La Corte Suprema, en fallo de fecha 12 de agosto de 2010, Rol No 5143-2010, ha reconocido en forma expresa que en la fusión el traspaso opera ministerio legis, sosteniendo que en virtud del artículo 99 de la LSA 
"(...) por el solo ministerio de la ley, se radican en el ente que persiste o que se constituye con motivo de la fusión todos los bienes y obligaciones de los entes que se fusionan. "Por consiguiente, en la fusión no existe transferencia de bienes determinados, ni asunción de deudas. La fusión comprende aportes de patrimonios o universalidades y una sucesión que opera por el solo ministerio de la ley de activos y pasivos, con todas las consecuencias jurídicas que ello importa, especialmente en materia tributaria"'".

Y en relación a las fusiones impropias, tanto la SVS como el SII han señalado que el título y el modo de adquirir es la ley y no una convención (Of. № 3465, de 13 de septiembre de 2005, del SII).

\section{Replanteamiento. La división como supuesto de sucesión universal parcial}

\subsection{La distribución patrimonial como fundamento de la sucesión universal parcial}

Como hemos adelantado, la conceptualización de la división como un supuesto de asignación de derechos pre-existentes se estructura sobre una consideración que, a nuestro juicio, es errónea: la asimilación de la idea de comunidad con la de patrimonio social. A partir de dicha homologación los organismos reguladores justifican el efecto esencial de la operación, consistente en la permanencia, en términos idénticos a los originales, de las relaciones jurídicas que son objeto de división. Sin embargo, tal asimilación adolece de un error de base que destruye el presupuesto normativo sobre el cual se estructura toda la institución, consistente en la asimilación entre comunidad y patrimonio social, cuando en realidad se trata de conceptos totalmente diversos. En efecto, mientras la comunidad es un cuasi-contrato, el patrimonio social es un atributo de la personalidad, que forma parte de una persona jurídica de naturaleza contractual (la sociedad). Dicho error conceptual conlleva que no sea jurídicamente adecuado hablar de la adjudicación de derechos pre-existentes, sino que lisa y llanamente de una enajenación ${ }^{70}$ de bienes a favor de un tercero (la nueva sociedad), afectándose así uno de los elementos que justifican la división de sociedades: la permanencia de las relaciones jurídicas traspasadas.

En virtud de lo expuesto, estimamos que los efectos de la división de sociedades se explican más claramente si se considera, como se hace en la doctrina y legislaciones comparadas, como un supuesto de sucesión universal inter vivos en una cuota del patrimonio originario, en la que la nueva sociedad (o sociedades) adquiere la titularidad del patrimonio correspondiente, en virtud de la ley, en concreto, del artículo 94 de la LSA. De esta manera, efectuada la

70 Alessandri (1984), p. 155; LIRA (1948), pp. 201-202. 
división y todos su trámites correspondientes, la nueva o nuevas sociedades se constituyen en sucesoras universales, en la porción que a cada una le corresponda, de la sociedad dividida. Se trata por tanto de un supuesto de sucesión universal parcial, según se desarrollará en el punto siguiente.

Afirmado lo anterior, cabe preguntarse entonces cómo calza dicha interpretación con el tenor literal de los artículos 94 y 95 de la LSA, en el entendido de que no cabe extender analógicamente lo dispuesto en el artículo 99 de dicha ley a los supuestos de división de sociedades anónimas. Es decir, la fundamentación de la sucesión universal en materia de división de sociedades anónimas debe encontrarse en la propia regulación que de la división efectúa la LSA. A tal fin es fundamental la idea de que la división de sociedades, como lo indica la propia LSA (artículos 94 y $95 \mathrm{~N}^{\circ} 1$ ), implica la distribución de un patrimonio entre dos o más sociedades constituidas al efecto ${ }^{71}$. Así, el análisis debe centrarse en las consecuencias jurídicas que se derivan de que la LSA se haya referido a la división de sociedades como un supuesto de división de patrimonios.

Según se desprende del tenor de la LSA, el patrimonio de una sociedad anónima constituye una universalidad jurídica ${ }^{72}$, desde que dicha ley se refiere a éste de manera general, caracterizándose por una composición dual (activo y pasivo $)^{73}$ y cuya razón de ser directa e inmediata son los aportes efectuados por los socios, sin perjuicio de que posteriormente su contenido se separe de lo aportado inicialmente, como consecuencia de la propia operatoria societaria. Dado lo anterior, el patrimonio, en tanto que universalidad, engloba "(...) eventualmente bienes diversos por su naturaleza y su origen, que constituyen una unidad abstracta", de forma que ésta se considera como un todo diverso de cada uno de los elementos que la componen, $y$ "(...) [l] os bienes que forman la universalidad son considerados no en su individualidad física o material, sino en su valor" ${ }^{\prime \prime 7}$.

\footnotetext{
${ }^{71}$ En general, en relación al patrimonio es posible consultar en nuestro país los siguientes trabajos: Fuenzalida (1961); Bustamante (1979); Figueroa (1997), Niño (1993-1994). En la doctrina extranjera: Olivencia (1978), pp. 500-501; Díez-Picazo y Gullón (2002), pp. 376-384.

72 Así expresamente, Puelma (2001), p. 198.

${ }^{73}$ Muy expresivo es el inciso final del artículo 10 de la LSA en cuanto identifica algunas de las partidas que componen el patrimonio social, refiriéndose a las cuentas del capital pagado, las de utilidades retenidas y otras cuentas representativas del patrimonio.

${ }^{74}$ SiLva (1985), p. 55. Esta misma consideración puede verse en OLIVENCIA (1978) pp. 500-502. Es posible considerar que nos encontramos ante una universalidad patrimonial cuando existe una pluralidad ontológica de bienes, susceptibles de ser objeto de actos y relaciones singulares; cuando existe una unidad lógica de su conjunto, que atribuye al todo un destino unitario; y cuando existe una consideración jurídica del conjunto por medio de la fijación normativa de una disciplina relativa a dicho conjunto, como unidad lógica, y no a los singulares bienes que lo componen. BustamANTE (1979), p. 71.
} 
Partiendo de dicha premisa, cabe postular que los artículos 94 y $95 \mathrm{~N}^{\circ} 1$ de la LSA constituyen reflejo de la conceptualización objetiva o finalista del patrimonio, desde que dichos preceptos reconocen expresamente la posibilidad de división del patrimonio societario. Con ello se evitan interpretaciones que, descansando más de lo deseable en la idea de patrimonio como atributo de la personalidad ${ }^{75}$, Ilevan a reducir la operación de división societaria al mero traspaso de las cuentas representativas del patrimonio, es decir, de la organización jurídico-administrativa de una sociedad, con el posterior traspaso o transferencia de los bienes y obligaciones que respaldan en los hechos dicha organización ${ }^{76}$. En nuestro concepto, tal interpretación obvia el sentido claro de la norma, que habla derechamente de la distribución del patrimonio; conlleva una aplicación exagerada de conceptualizaciones decimonónicas superadas tanto por la realidad como por el Derecho positivo ${ }^{77}$; e implica además reducir considerablemente las verdaderas consecuencias jurídicas de la operación de división de sociedades, ya que las cuentas representativas del patrimonio (asientos contables para la LSA, ex artículo 73) son sólo eso: representaciones de los bienes y obligaciones que conforman un patrimonio, siendo estos elementos, per se, lo verdaderamente sustancial de un patrimonio, con independencia de cómo los mismos son reflejados ad extra y siendo su consideración unitaria la que determina asimismo que el patrimonio se califique como una universalidad de Derecho $^{78}$.

\footnotetext{
75 En efecto, la doctrina ha criticado la postura tradicional de sostener que el patrimonio es un atributo de la personalidad, ya que si fuera así, llevada esa idea al extremo, debería sostenerse que el patrimonio no es susceptible de transmitirse, ya que el mismo debería desaparecer con la muerte de la persona. Figueroa (1997), p. 113. En sentido similar se ha afirmado que "(...) lo que sí es evidente que hoy en día no puede ya aceptarse la noción de que una persona sólo puede tener un patrimonio intraspasable e indivisible". Aвeluuk (1983), p. 47. Tampoco considera al patrimonio como un atributo de la personalidad, NIÑO (1993-1994), p. 159.

76 LYON (2003), pp. 205-207.

77 Como es sabido, desde la promulgación de la Ley $N^{\circ}$ 19.857, publicada en el Diario Oficial de 11 de febrero de 2003, que autoriza la constitución de la Empresa Individual de Responsabilidad Limitada (EIRL), en nuestro ordenamiento se permite que una persona constituya un patrimonio de afectación dotado de personalidad jurídica. Por lo demás, nuestro propio Código Civil conoce supuestos patrimoniales que parecen contravenir los principios de su consideración como atributo de la personalidad. Es el caso de la herencia yacente, en el que existe un patrimonio sin titular o de los diversos patrimonios separados que reconoce el Código Civil (el patrimonio común o social, el patrimonio propio del marido, el patrimonio propio de la mujer, junto al patrimonio reservado de ésta, o el peculio profesional o industrial del hijo menor sometido a patria potestad, sólo por nombrar algunos). Lo expuesto constituye una manifestación de la teoría objetiva del patrimonio. Al respecto, AlESSANDRI et al. (1998), pp. 480482. Asimismo, RafFray (2011), pp. 1-23.

78 Por lo mismo la fusión se califica como una "forma de transmisión de una universalidad". Pérez MILLA (1996), p. 176.
} 
Precisamente, es el carácter unitario propio de las universalidades jurídicas el que permite la posibilidad de un acto único de disposición respecto de dicha universalidad" ${ }^{79}$, siendo, de hecho, la "traspasabilidad" ipso iure del patrimonio, y por ende, de los bienes y obligaciones que lo componen, uno de sus elementos característicos, en tanto que universalidad jurídica ${ }^{80}$. Esta idea ya puede apreciarse en un dictamen emitido en el año 1968 por la Dirección General de Impuestos Internos, en el que sostuvo que "(...) la venta del activo y pasivo de una sociedad es un acto jurídico de carácter universal que no admite la distinción entre bienes muebles e inmuebles, salvo norma expresa de la ley [...] si bien la ley no se ha ocupado de un modo sistemático de las universalidades, existen en cambio disposiciones aisladas que permiten concluir que constituyen un bien distinto de los diversos bienes individuales que las forman, y que pueden ser objeto de actos jurídicos..." [la cursiva es nuestra] ${ }^{81}$.

De ahí que, aun cuando el artículo 94 de la LSA no aluda en forma expresa a que la distribución del patrimonio se realiza como un todo en virtud del expediente de la sucesión universal -como sí se hace en sede de fusiones, al utilizar el término "sucede"-, el carácter de universalidad jurídica del patrimonio societario conlleva necesariamente la idea de que el traspaso que se realiza del patrimonio social en virtud de la división de sociedades, lo es a título universal, en las proporciones que al efecto se acuerdan por la Junta de socios: trátase por tanto de un supuesto de sucesión universal parcia/22.

La LSA no se refiere en forma expresa al traspaso o distribución de los bienes particulares que integran el patrimonio, sino que se refiere lisa y llanamente al traspaso/distribución del patrimonio, es decir, del conjunto de bienes y obligaciones, de forma que los bienes y obligaciones que se traspasan lo hacen como una unidad. El propio artículo 99 de la LSA alude al patrimonio como un todo, como una universalidad, por lo que, desde un punto vista sistemático, parece apropiado comprender del mismo modo al patrimonio en sede de división de sociedades. Por tanto, el reconocimiento expreso del supuesto de traspaso a título universal en sede de división de sociedades no viene de la mano del término "sucede", como ocurre en sede de fusión, sino que de la frase "distribución de su patrimonio" y "distribución del patrimonio" a que aluden los artículos 94 y 95 de la LSA, respectivamente. El traspaso de una masa patrimonial como

\footnotetext{
79 Duccl (1995), p. 190.

${ }^{80}$ Esta idea puede verse en Garrigues (1976), p. 171. Asimismo, Morles (2007), p. 222. En nuestro país, Arteaga (2002), p. 606.

${ }^{81}$ Boletín del SII, año 15, № 170, 1968, p. 5806.

82 La cual no es ajena a nuestro ordenamiento, sino que por el contrario, es reconocida en el artículo 951 inciso $2^{\circ}$ del Código Civil.
} 
tal, como universalidad, no como bienes independientes, sólo puede operarse por la técnica de la sucesión. De ahí que en la alusión que la LSA hace a la distribución de patrimonios se encuentra ínsita la institución de la sucesión. Es posible afirmar que tales consideraciones sustentan el artículo 149 del nuevo RSA, que señala en forma expresa que "Cada nueva sociedad que se constituye producto de la división, se reputará haber sucedido inmediata y exclusivamente a la sociedad dividida respecto de los bienes que se le hubieren asignado" [la cursiva es nuestra].

\subsection{Operatoria de la sucesión universal parcial en la división de sociedades}

Finalmente, atendidas las propuestas efectuadas, resta por señalar cómo opera la técnica de la sucesión universal en el ámbito de la división societaria.

\section{a) Traspaso patrimonial parcial in universum ius}

En primer lugar, como se expuso, en la división societaria la sucesión universal opera en forma parcial. Ello quiere decir que el objeto de dicho traspaso es una porción patrimonial conformada por un conjunto de relaciones activas y pasivas debidamente individualizadas ${ }^{83}$, las cuales pasan a situarse en otro titular. Como consecuencia de dicho desplazamiento patrimonial, la nueva sociedad que recibió las correspondientes porciones patrimoniales viene a suceder al antiguo titular en todas las relaciones activas y pasivas que conforman el patrimonio traspasado. Algo de esta idea trasunta el artículo 149 del nuevo Reglamento de la LSA, al disponer que "Cada nueva sociedad que se constituye producto de la división se reputará haber sucedido inmediata y exclusivamente a la sociedad dividida respecto de los bienes que se le hubieren asignado" [la cursiva es nuestra].

Precisamente, debido a que la ley autoriza la división del patrimonio, en tanto universalidad jurídica, las porciones escindidas deben estructurarse de igual manera que el patrimonio del que proceden, vale decir, deben contar con un activo y un pasivo. Es la necesaria conformación dual del patrimonio, así como el principio de realidad del capital social ${ }^{84}$, lo que ha motivado la negativa del SII a la posibilidad de Ilevar a cabo una división en cuya virtud una de las nuevas sociedades reciba mayores pasivos que activos exigibles de la sociedad dividida ${ }^{85}$.

\footnotetext{
${ }^{83}$ Por ello el artículo 147 letra d) del Reglamento de la LSA exige que se efectúe la descripción de los activos que se asignan y de los pasivos que se delegan a las nuevas sociedades.

${ }^{84}$ Quijano y Esteban (2009), p. 566, nota al pie No 18.

${ }^{85} \mathrm{Al}$ efecto, el referido órgano ha indicado que: “(...) por aplicación de la normativa anteriormente reseñada, fluye como consecuencia ineludible que una sociedad objeto de división debe tener nece-
} 
Tratándose de relaciones jurídicas intuitu personae, es decir, aquellas en las que la figura del titular posee una relevancia fundamental, vinculándose indefectiblemente su razón de ser a una determinada persona, de forma que los derechos y/u obligaciones que se derivan del negocio existen en atención a la identidad de las partes (como por ejemplo, el usufructo -artículo 773 del Código Civil-o el derecho de uso -artículo 819 del Código Civil-), cabe cuestionarse la operatoria de la técnica de sucesión universal. En nuestro ordenamiento jurídico no se aprecian normas que resuelvan el asunto ${ }^{86}$, aun cuando en sede de fusiones, tanto el $\mathrm{SII}^{87}$ Como la Corte Suprema ${ }^{88}$ han reconocido que determi-

sariamente un patrimonio real a distribuir, que no es otro que su patrimonio neto, por lo cual resulta inconcebible la situación planteada por el ocurrente en que, a consecuencia de este proceso de división, una de las sociedades resulta con un patrimonio negativo, entendiéndose que esta situación se produce cuando el pasivo de una sociedad excede a su patrimonio, y en este sentido más que un inconveniente de orden tributario existe una imposibilidad jurídica de efectuar una división en tales términos, considerando las reglas generales sobre el contrato de sociedad establecidas en el Título XXVIII del Código Civil, específicamente en el artículo 2.055, que dispone que no hay sociedad si cada uno de los socios no pone algo en común, ya consista en dinero o efectos, ya en una industria, servicio o trabajo apreciable en dinero. De ahí que el artículo 94 de la Ley № 18.046 emplee la expresión "distribución de su patrimonio entre sí y una o más sociedades que se constituyan al efecto". 5.- En consecuencia, por las razones anotadas, debe concluirse que en un proceso de división de una sociedad, sea ésta de cualquier naturaleza, en tanto no exista un patrimonio neto a repartir o a distribuir y que es objeto de división, no puede llevarse a cabo tal figura jurídica, debiendo en todo caso las sociedades resultantes poseer necesariamente una parte de dicho patrimonio." (Oficio № 3.382, de 10 de diciembre de 1998).

${ }^{86}$ Como ocurre en Argentina, en donde el artículo 1195 del Código Civil dispone que "Los efectos de los contratos se extienden activa y pasivamente a los herederos y sucesores universales, a no ser que las obligaciones que nacieren de ellos fuesen inherentes a la persona, o que resultase lo contrario de una disposición expresa de la ley, de una cláusula del contrato, o de su naturaleza misma" [la cursiva es nuestra].

${ }^{87}$ Por Of. Ord. № 1046, de 4 de mayo de 2011, el SII ha excluido a los derechos personalísimos de los efectos de la fusión, señalando que “(...) al producirse la fusión caracterizada por la transmisión íntegra del patrimonio de una o más sociedades que se disuelven a la sociedad absorbente, ésta, vale decir la subsistente sucede, por disposición de la Ley, a la o a las sociedades extintas en el conjunto de sus derechos y facultades que en dichos patrimonios se radicaban, con excepción de aquellos que se califiquen como de carácter personalísimos, según ha señalado con anterioridad este Servicio" [la cursiva es nuestra]. Previamente, por Of. № 6348, de 2003, el SII sostuvo que "(...) a pesar que la norma se refiere a la sucesión en "todos los derechos y obligaciones", ésta debe entenderse restringida a aquellos derechos adquiridos y obligaciones que pueden ser ejercidos (o cumplidas) por otras personas. De esta manera, la facultad de depreciar aceleradamente bienes físicos del activo inmovilizado no integra la sucesión, porque sólo puede ejercerla quién adquirió nuevos o internó los referidos bienes y no quién los recibió de esa persona" [la cursiva es nuestra].

${ }^{88}$ Fallo de fecha 14 de junio de 2011 (Rol № 1121-2009), en el que la Corte reconoció el carácter de derecho patrimonial personalísimo a las "pérdidas" tributarias, y a la posibilidad de su utilización. Al respecto, la Corte sostuvo que “(...) El hecho posterior que permite la recuperación es la fusión, que si bien conlleva una unión absoluta de patrimonios en cuanto a activos y pasivos, no involucra las pérdidas, pues éstas constituyen un derecho de carácter patrimonial para la persona jurídica que las generó y es esa persona quien puede deducirlas de sus propias utilidades; ergo, si quien las deduce es la sociedad absorbente, quien no ha generado utilidades, por el contrario se está beneficiando de las 
nados derechos personalísimos no son susceptibles de traspaso en virtud de la sucesión universal. Dogmáticamente, creemos que en principio tanto la fusión como la división sí pueden dar lugar al traspaso de relaciones jurídicas intuitu personae, ya que los efectos de las operaciones se encuentran dispuestos ex lege, sin que se contemplen excepciones legales a los mismos ${ }^{89}$. Sin perjuicio de ello, no es posible desconocer que determinados negocios pueden perder su razón de ser en el supuesto que, como consecuencia de la operación, en una relación contractual ingrese quien originalmente era un extraneus respecto a ella. En este caso cobra relevancia la inaplicabilidad en los supuestos de sucesión universal, de las normas generales sobre novación subjetiva (por los motivos que se indican seguidamente), y de las reglas comunes que el Código Civil contiene sobre cesión de créditos, ex artículo 1908 de dicho Código. Así, dichas regulaciones no prestan auxilio en relación a esta cuestión. Asimismo, cabe descartar de plano la posibilidad de aplicar lo dispuesto en el artículo 1455 inciso primero del Código Civil, en cuanto a que "El error acerca de la persona con quien se tiene intención en contratar no vicia el consentimiento, salvo que la consideración de esta persona sea la causa principal del contrato" [la cursiva es nuestra]. En efecto, tal disposición regula el error in personam como un supuesto de vicio originario y no sobreviniente, no pudiendo hacerse extensiva dicha disposición a éstos, atendido el carácter restrictivo con que han de interpretarse los vicios del consentimiento. Así, la posibilidad de solicitar la resolución del contrato debe vincularse con el carácter causal que puede poseer la identidad de una de las partes contractuales. Tal carácter se reconoce por el propio Código Civil, al señalar que la consideración de una persona puede ser la causa principal de un contrato (artículo 1445). Desde dicho prisma, la desaparición de la causa del negocio, en el entendido que la propia identidad de la sociedad que se fusiona o divide fue el elemento esencial, el motivo, en la terminología del artículo 1467 del Código Civil, que justificó la concreción del mismo ${ }^{90}$, nos posiciona ante un supuesto de ausencia o desaparición sobrevenida de la causa, sancionable con la nulidad absoluta ${ }^{91}$.

producidas por un ente distinto -la sociedad absorbida- ello constituye un incremento de patrimonio y por ende afecto a tributación. En efecto, el numeral $3^{\circ}$ del artículo 31 de la Ley de Impuesto a la Renta en ninguna parte se refiere a las sociedades fusionadas, por lo que resulta evidente que la norma está consagrada en beneficio del negocio o empresa que ha incurrido en el desembolso, cuyo no es el caso de la nueva sociedad".

${ }^{89}$ No es de aplicación lo dispuesto en el artículo 1464 № 3 del Código Civil, que dispone que hay objeto ilícito en la enajenación de los derechos o privilegios que no pueden transferirse a otra persona, ya que ni en la fusión ni en la división hay enajenación de bienes y derechos.

90 Motos Guirao (1953), p. 414; Cortés Domínguez y Pérez Troya (2008), pp. 67-69.

91 Ducci Claro (1995), pp. 316-317; Vial Del Río (2003), p. 211; Rivera Restrepo (2011), p. 334. 
En lo que respecta a las relaciones pasivas, es interesante destacar que no solo la doctrina ${ }^{92}$ y alguna jurisprudencia ${ }^{93}$, sino que ahora también los incisos $2^{\circ}$ y $3^{\circ}$ del artículo 149 del nuevo Reglamento de la LSA, asumen la aplicabilidad de las reglas generales sobre novación subjetiva por cambio de deudor, en particular, lo establecido en el artículo 1635 del Código Civil, al señalar que "La delegación de obligaciones de la sociedad dividida a una sociedad que se crea producto de la división, no produce novación si el acreedor no expresa su voluntad de dar por libre a la sociedad dividida. A falta del consentimiento del acreedor, se entenderá que la nueva sociedad es solamente un diputado por la sociedad dividida para hacer el pago, o que, según se acordó en la junta de dicha sociedad, la nueva sociedad es solidaria o subsidiariamente responsable de esa obligación frente al acreedor".

Si bien tal solución del Derecho Común en principio parece razonable en cuanto a sus consecuencias ${ }^{94}$, colisiona dogmáticamente con la comprensión de la división de sociedades como una operación de sucesión universal parcial ${ }^{95}$. En efecto, en la división de sociedades considerada como un supuesto sucesorio no cabe hablar de una verdadera novación subjetiva, dado que no existe una modificación de la figura del deudor en una relación obligacional individualmente considerada que se extingue como consecuencia de la operación (que es el presupuesto fáctico de la norma en cuestión), sino que se trata de un cambio general de titularidad de un conglomerado de relaciones jurídicas consideradas de manera conjunta y que conforman el patrimonio de la sociedad dividida ${ }^{96}$. Asimismo, con ocasión de la sucesión universal las relaciones jurídicas traspasadas no se extinguen, sino que se produce una subrogación ministerio legis, cambiando sólo el titular de la relación jurídica sin efecto novatorio alguno ${ }^{97}$. En tercer lugar, en aras de garantizar el traspaso eficaz y seguro de una porción patrimonial, la sucesión universal debe acarrear que la sociedad que se divide deje de responder por las deudas que fueron objeto de traspaso. Para ello, el legislador debe contemplar mecanismos de tutela que, a priori, tiendan a asegurar la debida protección de los acreedores sociales. En efecto, aun cuando

\footnotetext{
92 Hernández Adasme (2000), pp. 140-141; Lyon Puelma (2003), pp. 214-215; Sandoval López (2010), pp. 401-402.

${ }^{93}$ El fallo de 9 de mayo de 2002, del 24 Juzgado Civil de Santiago (Rol C-822-1999), en el que se reconoce la inoponibilidad de la división de sociedades anónimas si falta el consentimiento del acreedor.

${ }_{94}$ De hecho, en diversos países europeos se contemplan normas que regulan la responsabilidad de las sociedades partícipes en una operación de división. Un análisis de ellas en EsCRIBANo Gamir (2011), p. 5.

95 Quijano y Esteban (2009), p. 578-579; Escribano Gamir (2011), p. 15; Garrido De Palma (2012), p. 149.

96 Motos Guirao (1953), pp. 52-53. Respecto de la división, Quijano y Esteban (2009), p. 555.

97 Aparentemente en este sentido, Ríos (2008), p. 176.
} 
en el Derecho comparado se ha seguido el sistema de imponer una responsabilidad solidaria o subsidiaria de cargo de la sociedad que se divide, respecto de las deudas traspasadas a la nueva sociedad, la doctrina ${ }^{98}$ ha criticado la real eficacia de dicho modelo tutelar. Los cuestionamientos apuntan a que dicho sistema opera en detrimento del resto de acreedores cuyos créditos se mantuvieron radicados en el patrimonio de la sociedad dividida. Debido a que dicho patrimonio finalmente responderá no sólo de las deudas que lo conforman, sino que eventualmente de otras deudas (las de la nueva sociedad), el sistema de tutela en análisis no funciona sino sólo a favor de los acreedores cuyos créditos fueron traspasados a la nueva sociedad, ya que, respecto de los acreedores de la sociedad dividida, el referido sistema tiende a reducir el patrimonio llamado a responder de sus créditos.

\section{b) Traspaso patrimonial uno actu}

En segundo lugar, el traspaso patrimonial se efectúa uno actu, es decir, en virtud de un único acto, sin que sea necesario cumplir con las formalidades específicas que contempla el Derecho Común para la circulación de los diferentes bienes y derechos que integran el patrimonio objeto de traspaso. Ello quiere decir que el cumplimiento de las formalidades inherentes a la operación de división (inscripción registral en el Registro de Comercio y publicación) genera en forma inmediata, sin la necesidad de mayores solemnidades, el traspaso de todos y cada uno de los bienes que conforman el patrimonio dividido. Ello implica que el patrimonio dividido se radica en la nueva sociedad exactamente en el mismo momento en el que ésta es creada, lo cual puede corroborarse de la lectura concordada de los artículos 148, 149 y 150 del Reglamento de la LSA.

En forma particular, lo anterior implica reconocer que la LSA contiene una modificación al régimen común de transferencia de dominio de los inmuebles, el cual en principio debería efectuarse sólo por medio de la inscripción conservatoria, por aplicación del inciso primero del artículo 588 del Código Civil, en relación con el inciso primero del artículo 686 del Código Civil ${ }^{99}$. Al

\footnotetext{
98 Conde (2004), p. 583; Quijano y Esteban (2009), p. 580.

99 En virtud de dichas disposiciones, se estima que en los supuestos de fusión de sociedades, el modo general de adquirir el dominio sobre los inmuebles es la tradición por medio de su inscripción conservatoria. Así, se ha señalado que "(...) la ley de sociedades anónimas estatuye un caso excepcional de sucesión patrimonial a título universal, en el caso de la fusión de sociedades. Ahora bien, cuando en los activos que por la fusión se comprenden bienes raíces, la tradición de éstos, de la sociedad que desaparece a la que subsiste o se crea, debe efectuarse mediante la correspondiente inscripción conservatoria, que no es válido substituir por una subinscripción marginal, asimilada al simple cambio de nombre que experimenta la sociedad transformada...". Feliú Segovia (2008), p. 95. En dicho sentido, se ha argumentado que "(...) la inscripción conservatoria constituye la manera en que se efectúa la tradición de los bienes raíces y en los casos en que dichos bienes se aportan o
} 
considerar que las normas de la LSA sobre división abrigan la posibilidad de ver en dicha operación un supuesto de sucesión universal, cabe estimar que el modo de adquirir en la división de sociedades es la ley, en tanto que es ésta la que determina cuáles son los efectos típicos de la operación y la forma en que estos surgen, lo que se verifica con el cumplimiento de la inscripción registral y posterior publicidad de la operación y no con la inscripción conservatoria particular de los respectivos inmuebles ${ }^{100}$, lo cual, como se expuso, ya ha sido reconocido para las fusiones por nuestros tribunales de justicia. En este sentido, cabe comprender que la LSA ha modificado el régimen general de tradición de los inmuebles contenido en el Código Civil, previendo un sistema particular para esta operación -y la fusión-. Esta concepción ha sido potenciada por el nuevo RSA, al señalar su artículo 148, sobre la base del artículo $3^{\circ}$ de la LSA, que se considerará como fecha de constitución de la nueva sociedad aquella en que surta efecto la división, de acuerdo al artículo $5^{\circ}$ del Reglamento, sin que este último artículo supedite los efectos de la fusión a inscripciones especiales de ninguna naturaleza. Sólo de esta manera se comprenden plenamente los efectos reales de la división y se da cobijo a la finalidad económica de la operación, que radica en garantizar la simplicidad circulatoria de los patrimonios societarios.

\section{c) Traspaso patrimonial ex lege}

Atendidas las particulares consecuencias de la sucesión universal parcial, la ley es la única fuente capaz de consagrarla, de forma que sólo ella puede reconocer la posibilidad de que una sociedad se divida por medio del expediente de la sucesión universal. Así puede desprenderse del fallo de fecha 6 de

adquieren dentro de un proceso de división o fusión por una sociedad que no es continuadora de la sociedad propietaria, la única forma de efectuar la tradición es la inscripción nueva que se practique. En estos casos, el título traslaticio de dominio está constituido por los contratos y acuerdos de voluntades suscritos o adoptados por las sociedades involucradas en el proceso de disolución, división o fusión de que se trate [...] Claramente la LSA reguló la división, transformación y fusión de las sociedades anónimas en los artículos 94 y siguientes, pero no alteró ni modificó las disposiciones legales contenidas en el Código Civil sobre los bienes y los modos de adquirir el dominio de los mismos...". Revista Fojas (2004), № 13, Sección Jurisprudencia, Doctrina y Praxis Registral, Consulta $\mathrm{N}^{\circ} 3$, disponible en http://fojas.conservadores.cl/jurisprudencia/consulta-n\%C2\%BA3\%E2\%80\%93-edicion-n\%C2\%BA13, [visitado en: 31/10/2013].

100 Así, es acertado lo señalado por la doctrina en sede de fusiones cuanto a que "(...) [p]er gli immobili, in particolare, non è necessaria nè $l^{\prime}$ Auflassung nè $I^{\prime} E$ Eintragung come afferma invero la dottrina tedesca, bastando la registrazione della fusione per rendere operativo il trasferimento dei singoli beni che si verifica ope legis [...] II fenómeno acquisitivo ha, nella fusione, il suo presupposto in un único atto (l'iscrizione dell'atto di fusione, como si vedrà) e, una volta che questo sia eseguito, non ha rilievo, ai fini dell'acquisto, alcuna altra formalità: la trascrizione nei registri immobiliari è rilevante ai soli effetti pubblicitari" [la cursiva es nuestra]. SANTAGATA (1964), pp. 118-119. asimismo Claussen (1999), p. 123. 
agosto de 2009 (Rol No 1.347/09) de la Corte Suprema en materia de división de sociedades, en el que el máximo tribunal señaló que:

"(...) la división de la empresa en dos filiales, aun cuando éstas se encuentren relacionadas [...] no es posible de efectuar sin dar cumplimiento a la normativa que al efecto indica la Ley 18.046, conocida como Ley de sociedades anónimas y, cuya fiscalización, corresponde a la Superintendencia de Valores y Seguros; división que está expresamente reconocida y regulada en los artículos 94 y siguientes de la referida ley..." (Considerando 9).

Así, de todo lo indicado se desprende que en la división de sociedades, al igual que en la fusión de sociedades ${ }^{101}$, el modo de adquirir es la ley, el cual, pese a no estar recogido en el artículo 588 del CC, es reconocido por la doctrina, lo que se condice con la comprensión común de la división de sociedades como la cara opuesta de la fusión. Asimismo, el tratamiento unificado que la LSA da a estas dos instituciones responde a la similitud conceptual de ambas, por lo que construirlas de maneras tan opuestas como se ha hecho por la SVS y el SII parece atentar directamente contra la esencia de las mismas y desvirtuarlas hasta hacer desaparecer sus contornos inherentes.

\section{División de sociedades no anónimas, sucesión universal y autonomía de la voluntad}

Visto que en la división de sociedades anónimas es posible sostener que el ordenamiento jurídico contempla un supuesto de sucesión universal parcial, queda por determinar si tal expediente técnico puede aplicarse asimismo a las operaciones de división total y a las efectuadas por sociedades no anónimas. Como se apuntó previamente, la praxis nacional y la jurisprudencia administrativa del SII han estimado que es posible la realización de operaciones de división total ${ }^{102}$ y entre tipos societarios diversos a la sociedad anónima ${ }^{103}$, en virtud del principio de autonomía de la voluntad. Sin embargo, ni la ley tributaria ni el SIl se han pronunciado en cuanto a si tal operación se materializa por medio del expediente técnico de la sucesión universal parcial.

\subsection{El carácter legal de los modos de adquirir como límite a la autonomía privada}

En general, el comprender por qué la doctrina ha venido fundando la viabilidad de esta operación en el principio de la autonomía privada requiere

101 En este sentido, Santagata (1964), pp. 355-356; Pérez Milla (1996), pp. 174-177.

102 Hernández (2000), pp. 115-116; Puelma (2001), p. 692; Sandoval (2010), p. 392.

103 BóRQuez (2002), pp. 65-69, apelando esencialmente a la legislación tributaria y al principio de autonomía de la voluntad. 
considerar a ésta como la "actividad y potestad de autorregulación de intereses y relaciones propias, desplegada por el mismo titular de ellas" en el campo del Derecho privado ${ }^{104}$, que ha sufrido un proceso de comercialización, común a todo el Derecho, ya que "El Derecho se "comercializa», y se postula la necesidad de atender con preferencia a "la seguridad del tráfico jurídico" [...] mantenién[dose] nominalmente el dogma de la autonomía de la voluntad, pero ya no como expresión de respeto a la libertad individual, sino como un eficaz instrumento para el desarrollo del comercio"105.

Los modos de adquirir el dominio sólo pueden consagrarse legalmente, como establece en forma clara el artículo $19 \mathrm{~N}^{\circ} 24$ inciso segundo de la Constitución Política ${ }^{106}$. En este sentido, debe considerarse que esta garantía constitucional opera como una verdadera limitación a la autonomía privada en su vertiente de libertad negocial, desde que impide que los particulares creen por sí nuevos modos de adquirir. Desde luego que en este caso no es la ley el modo de adquirir, ya que ésta no contempla el traspaso patrimonial parcial uno actu para otros tipos sociales diversos a la sociedad anónima. Tal limitación no debe extrañarnos, si consideramos que los derechos fundamentales, junto a su vertiente atributiva subjetiva, poseen una vertiente atributiva objetiva, en cuya virtud operan como verdadera "guía para la producción e interpretación de las restantes normas del ordenamiento" ${ }^{\prime 107}$.

Asimismo, lo anterior se condice con la limitación que tradicionalmente opera en relación a la autonomía de la voluntad, esto es, el orden público (artículos 1461 y 1467 del Código Civil), entendido en forma general como aquello en que está comprometido el interés superior, en el cual se incluye precisamente lo relativo a los modos de adquirir el dominio ${ }^{108}$.

Por tanto, no encontrándose prevista en forma expresa la posibilidad de llevar a cabo operaciones de división societaria entre diversos tipos sociales, no cabe realizar las mismas, al menos, con los mismos efectos que se contemplan en sede de regulación de anónimas, por cuanto no existe un modo de adquirir que contemple la transferencia de forma universal y parcial de patrimonios de tipos que no sean sociedades anónimas.

104 BetTi (1943), pp. 46-47.

105 De Castro (1985), p. 15.

106 A este respecto se señala que "Los modos de adquirir están establecidos en la ley, y por el carácter institucional de la materia de propiedad, no pueden tenerse como tales sino los que el texto legal señala". Peñailillo (2002), p. 113.

107 AlCalde (2007), p. 20.

108 Vial (2003), pp. 59-60. Asimismo, León Hurtado (1991), pp. 46-52. 


\subsection{La excepcionalidad como límite de la autonomía privada}

Sin perjuicio de lo señalado, la obtención de los efectos inherentes a la sucesión universal queda igualmente excluida del ámbito de la autonomía privada, atendidas las excepcionales consecuencias que dicha técnica conlleva en cuanto al traspaso de bienes y obligaciones, operando dicha consideración como verdadera piedra de tope respecto de la autonomía privada. En efecto, como se ha expuesto al tratar de la técnica de la sucesión universal (total o parcial) la misma tiene como consecuencia esencial el permitir el traspaso de masas de bienes heterogéneas por medio de un solo acto y como un todo.

Esta posibilidad constituye una excepción al principio legal de especialidad circulatoria, por cuanto permite reconducir todos los trámites particulares que deben realizarse para la transferencia de determinados bienes, de acuerdo a la naturaleza de cada uno, a un único trámite general, con efectos para todos los tipos de bienes ${ }^{109}$. Y como tal excepción a una norma legal, requiere constar en una norma de igual rango.

Por otra parte, no es posible obviar que el considerar a la autonomía de la voluntad -y por ende, al contrato- como susceptible de generar por sí una transferencia patrimonial in universum ius (total o parcial) y uno actu implica otorgar verdaderos efectos reales (erga omnes) a dicho contrato, invistiéndolo del carácter de modo de adquirir, diverso de aquellos contemplados en el artículo 588 del Código Civil o distinto a la ley misma ${ }^{110}$. Tal posición, por tanto, confunde el título con el modo.

Así, en esta materia no cabe adosar al contrato los señalados efectos reales, sino que como se indicó en el punto anterior, es menester recurrir a la ley a fin de determinar el modo de adquirir que opera en estos negocios. Precisamente por tal motivo se ha dicho que "La sucesión, en este significado técnico, es materia cuya disciplina está reservada a la privativa competencia normativa de la ley, del orden jurídico, y se sustrae a la autonomía privada"111, afirmación la cual

109 Eberhard (1999), p. 57; Cortés y Pérez (2008), pp. 63-64.

110 Por ello se ha señalado con acierto respecto de la fusión que "La concepción de la fusión como acto jurídico complejo donde es necesaria una exteriorización unilateral de la voluntad pero cuyos efectos se producen "ex lege" (con independencia de que la voluntad esté dirigida o no a la obtención de tal resultado) indican que es el Derecho quien ordena la transmisión universal. Este efecto no se genera como consecuencia de las voluntades de las sociedades (no es el efecto de un «contrato» de fusión), sino que es un elemento más del proceso que tiene lugar siempre que se proceda de forma jurídicamente adecuada. [...] La configuración ex lege de la institución es querida por el legislador que permite la sucesión universal como método cuasiprivilegiado de transmisión para este supuesto, en atención a la función económica perseguida...". Pérez MiLla (1996), pp. 175-176. Tales afirmaciones son extrapolables sin mayores dificultades a la división de sociedades.

111 BetTI (1943), p. 29. En nuestro país en relación a la sucesión mortis causa se ha señalado en términos similares que "(...) el contrato no es un título traslaticio de dominio apto para convertir a una 
no constituye sino un principio general de la operatoria de la técnica sucesoria que cabe ser considerado a la hora de analizar la posibilidad de reconocer a la autonomía de la voluntad como susceptible de generar una sucesión universal. Y es dicho carácter excepcional el que impide extender los efectos de la citada técnica más allá de los supuestos legalmente considerados ${ }^{112}$.

En este sentido, parece adecuado traer a colación aquí nuevamente lo señalado hace ya varios años por el Consejo de Defensa del Estado, en cuanto a la autonomía de la voluntad como fundante de la posibilidad de efectuar una fusión entre entidades para las cuales el ordenamiento jurídico no había previsto tal opción. El Consejo de Defensa sostuvo que "no basta, para justificar la fusión, que en derecho privado los particulares pueden hacer todo lo que no se encuentre prohibido por la ley o que no sea contrario al orden público o a las buenas costumbres. Porque no es efectivo, en doctrina jurídica sana, que el principio de autonomía de la voluntad -una de las bases del derecho privado contractual- autorice a los particulares para crear, mediante su manifestación de voluntad, las figuras y relaciones jurídicas que se les antojen, en la forma y con los efectos que arbitrariamente quieran [...] Se desprende de lo anterior, que la posibilidad de admitir la figura jurídica de la fusión de corporaciones, en definitiva tiene que ser examinada y debe serlo, a la luz de los preceptos de la legislación positiva que regla la constitución, funcionamiento y extinción de ellas, y no basta sostener que es posible porque es querida por las corporaciones que se unen"113. Así, la posibilidad de llevar a cabo determinada operación queda sujeta a lo dispuesto en su régimen normativo, debiendo estarse a lo que sus disposiciones contemplen al efecto y teniendo en cuenta en ello las limitaciones propias que se desprenden del ordenamiento jurídico.

\section{Conclusiones}

Por los argumentos expuestos es posible comprender que el traspaso patrimonial existente en la división de sociedades opera uno actu, es decir, como un todo, abarcando las titularidades y relaciones jurídicas activas y pasivas de la masa patrimonial escindida y perfeccionándose con el cumplimiento de las solemnidades particulares previstas para la operación y las generales que con-

persona en sucesor a título universal de otra, esto es, de todos sus bienes, derechos y obligaciones transmisibles". Bustamante (1998), p. 372.

112 Desde antaño (así, sentencia de fecha 15 abril de 1947) nuestra Corte Suprema ha sostenido que las normas de excepción no pueden aplicarse más allá de sus términos, por más aparentes que sean las razones de equidad o analogía que aconsejen otra cosa.

113 Informe № 882, de 19 de noviembre de 1970, en Consejo de Defensa Del Estado (1973), p. 530. Ello se ha resuelto sólo con la dictación de la Ley № 20.500, del año 2011, que reconoce la posibilidad de que las asociaciones (antes, corporaciones) puedan fusionarse. 
Ileva la modificación estatutaria de la sociedad dividida y la constitución de una nueva sociedad. Junto a ello se efectúa el traspaso de las masas sociales, el cual, pese a que el № 2 del artículo 95 de la LSA señala que opera de pleno derecho con la aprobación de los estatutos de la o de las nuevas sociedades a constituirse, no puede sino perfeccionarse realmente con el cumplimiento de las solemnidades inherentes a la constitución de la nueva o nuevas sociedades. En dicho momento opera el traspaso, sin perjuicio de su efecto retroactivo de acuerdo a lo dispuesto en el artículo $3^{\circ}$ de la LSA, lo cual ha sido ratificado recientemente por el artículo 148 del nuevo RSA, en relación con su artículo $5^{\circ}$.

En relación a la división de sociedades no anónimas, a nuestro juicio no cabe reconocer que los particulares puedan, en virtud de su mero arbitrio, acordar un traspaso de bienes in universum ius y uno actu, por cuanto ello implica precisamente permitir la creación de un modo de adquirir el dominio, especial, no reconocido en forma general por el ordenamiento jurídico, sin perjuicio obviamente de que la operación de división pueda llevarse a cabo siguiendo el principio de especialidad circulatoria de los bienes específicos. Ello se condice con que el orden público es uno de los límites al principio de autonomía de la voluntad, encuadrándose precisamente en dicho concepto los modos de adquirir el dominio. Lo señalado se complementa con la circunstancia consistente en que tal forma de traspaso implica excepcionar los sistemas particulares de circulación de los bienes que integran un patrimonio, individualmente considerados. E implica asimismo obviar las normas sobre novación subjetiva por cambio de deudor, ya que, en estricto rigor, con la técnica de la sucesión universal se busca evitar que la viabilidad de la operación dependa de la voluntad del acreedor social, que es un verdadero extraño en relación a la sociedad misma. Tal interpretación de las normas relativas a la división de sociedades es contraria a los principios hermenéuticos fundamentales de coherencia y consistencia del sistema jurídico que constituye las modificaciones estructurales, obviando o mejor dicho, atentando contra la conexión interna que la división tiene con otras operaciones que integran el tipo modificación estructural. Se atenta contra la unidad del sistema jurídico, por cuanto se construye a la división de sociedades de manera diferente a la que tiene dogmática y positivamente, de forma que la institución no aparece como integrada en el sistema constituido por las modificaciones estructurales, sino que más bien en la regulación de la partición de comunidades. Existe, por tanto, un inadecuado recurso al Derecho Civil como Derecho Común ${ }^{114}$, por cuanto no existe va-

114 Asumiendo que cabe el recurso al Derecho Civil como Derecho Común supletorio, posición que no es aceptada por toda la doctrina chilena en sede societaria. Así, se ha sostenido que "(...) la sociedad anónima se rige por normas propias y no se le aplican las reglas generales de las sociedades contenidas en el Código Civil. El Código Civil contiene algunos principios generales en 
cío alguno que llenar, o, de considerarse que éste existe, tal integración debe efectuarse de manera armónica, de forma que al operarse la integración no se destruya la especialidad de la institución.

Por el contrario, la interpretación aquí propuesta se condice plenamente con el espíritu de la LSA, como se puede constatar en el propio Mensaje de dicha ley. En éste se señala que la legislación de las sociedades anónimas pretende facilitar el desarrollo de dicho tipo social, teniendo presente al efecto "(...) la eficiencia de este tipo de organización empresarial en cuanto a transferencia de propiedad [...] y posibilidad de aunar rápidamente mayores capitales, lo cual deberá reflejarse en mayores facilidades y menores costos para el emprendimiento de nuevos negocios, aspecto que se ha hecho muy necesario dado el grado de dinamismo que fundamentalmente a través de la competencia externa ha adquirido nuestra economía"115. De esta forma la interpretación aquí sostenida se condice con la necesidad de adecuación de los negocios a los dinámicos cambios de la economía, a los que la sociedad anónima requiere adaptarse por medios rápidos y simples.

\section{Bibliografía CitADA}

Abeliuk Manasevich, René (1983): Las obligaciones, $2^{\text {a }}$ ed. (Chile, Ediar Editores). AlbORTCHIRE, Adamou (2005): Le sort des contrats dans les opérations de fusion et de scission de sociétés commerciales, Thése pour obtenir le grade de Docteur en Droit. Disponible en: http://tel.archives-ouvertes.fr [visitado el 12/02/2013].

Alcalde Rodríguez, Enrique (2007): La sociedad anónima. Autonomía privada, interés social y conflictos de interés (Chile, Ed. Jurídica).

materia de sociedades que el Código de Comercio no considera por implícitos. Las otras normas del Código Civil sobre sociedades no rigen en el ordenamiento mercantil pues este último contiene reglas específicas basadas en el carácter solemne de los tipos societarios que él trata, en la publicidad dispuesta en favor de terceros, para la cual contempla un régimen orgánico, al que la sociedad civil es completamente ajena. Materias tales como la nulidad, la extensión, las facultades de los órganos administradores, carácter y alcance, los abusos y desviaciones del ejercicio de las facultades, están regidas exclusivamente por el Código de Comercio y la legislación mercantil complementaria, de una manera específica y sistemática, lo que excluye la aplicación de las normas del Código Civil [...] La sociedad anónima tiene una normativa propia, que está fuera del Código de Comercio y que no contiene referencia supletoria alguna al Código Civil. Esto se reafirma en el artículo 138 de la Ley $\mathrm{N}^{\circ} 18.046$ de 22 de octubre de 1981, que introduce modificaciones al Código Civil, sustituyendo la definición de sociedad anónima que este cuerpo legal contenía, por la que ella da en su artículo primero. Asimismo se sustituye el artículo 2064 del Código Civil para dejar constancia que la sociedad anónima es siempre mercantil aun cuando se forme para la realización de negocios de carácter civil. Por ser una sociedad formalmente comercial, mercantil «per se», es lógico que sólo se rija por su legislación específica y técnica". Sandoval (1986), p. 80.

115 Historia de la Ley No 18.046, p. 88. 
AlesSAndri Rodríguez, Fernando (1984): Partición de bienes, explicaciones de clases revisadas por el profesor Alessandri: incluyen un modelo de juicio particional (Chile, Ediar Editores).

Alonso LeDESMA, Carmen (2009): "Segregación y constitución de sociedad íntegramente participada mediante transmisión del patrimonio", en: Rodríguez Artigas, Fernando (coord.) Modificaciones Estructurales de las Sociedades Mercantiles (España, Aranzadi Thomson Reuters), Tomo II, Traslado internacional del domicilio social, Escisión, Cesión global de activo y pasivo, Otras cuestiones, pp. 473-526.

Alonso UReBA, Alberto (2009): "La cesión global de activo y pasivo: elementos de caracterización, clases y régimen", en: Rodríguez Artigas, Fernando (coord.) Modificaciones Estructurales de las Sociedades Mercantiles (España, Aranzadi Thomson Reuters), Tomo II, Traslado internacional del domicilio social, Escisión, Cesión global de activo y pasivo, Otras cuestiones, pp. 629-672. Arteaga EcheverRía, Ignacio (2002): "En busca del concepto jurídico de empresa", en: $R C h D$ (Vol. 29, № 3), pp. 603-620.

Baeza Ovalle, Gonzalo (2003): Derecho Comercial (Chile, LexisNexis), Tomo II. BAINBRIDGE, Stephen (2003): Mergers and Acquisitions (USA, Foundation Press).

Ballester Colomer, Juan (1997): "Reorganizaciones de sociedades", en: La Notaría ( $N^{\circ}$ 9), pp. 115-136.

BANk, Steven A. (2004): "Tax, Corporate Governance, and Norms", en: Washington \& Lee Law Review (Vol. 61), pp. 1159-1232.

BetTI, Emilio (1943): Teoría general del negocio jurídico (traducción de Martín Pérez, A., España, Ed. Revista de Derecho Privado).

BEUTEL, David (2008): Der neue rechtliche Rahmen grenzüberschreitender Verschmelzungen in der EU. Einflüsse des Gemeinschaftsrechts auf die Schaffung nationaler Rechtsgrundlagen grenzüberschreitender Verschmelzungen unter Beteiligung deutscher Kapitalgesellschaften (Alemania, Herbert Utz Verlag).

Bórquez Pincheira, Aníbal (2002): "Notas acerca de la división de sociedades de responsabilidad limitada", en: Revista de Derecho, Universidad de Concepción ( $\mathrm{N}^{\circ} 211$, Año LXX), pp. 65-80.

BRON, Jan (2005): Grenzüberschreitende Verschmelzung von Kapitalgesellschaften in der $E G$, Beiträge zum Transnationalen Wirtschaftsrecht ( $\left.\mathrm{N}^{\circ} 41\right)$.

BurG, Arnaud, y OrY, Raphaël (2012): "Les limites au principe de transmission universelle du patrimoine dans les opérations de fusion", en: Fusions \& Acquisitions Magazine (mars-avril), pp. 79-80.

Bustamante SalazAr, Luis (1979): El patrimonio: dogmática jurídica (Chile, Ed. Jurídica). 
Bustamante Salazar, Luis (1998): "El efecto extintivo de la confusión en la enajenación de la herencia por un título oneroso", en: Revista de Derecho de la Universidad Católica de Valparaíso (XIX), pp. 371-381.

Cabanellas de las Cuevas, Guillermo (2009): Derecho Societario, Parte General, Escisión de sociedades (Argentina, Editorial Heliasta).

Camacho De Los Ríos, Javier (2004): La cesión global de activo y pasivo como mecanismo de liquidación y como supuesto de modificación estructural (España, Colegio de Registradores de la Propiedad y Mercantiles de España, Centro de Estudios).

CÁmARA, Héctor (1985): Derecho Societario. Estudios relacionados con las leyes 19.550 y 22.903 (Argentina, Ediciones Depalma).

Campobasso, Gian Franco (2002): Manuale di Diritto Commmerciale, $2^{\mathrm{a}}$ ed. (Italia, Utet).

CANARIS, Claus-Wilhelm (1998): El sistema en la jurisprudencia (Systemdenken und Systembegriff in der Jurisprudenz: entwickelt am Beispiel des deutschen Privatrechts),-2, Berlin, 1983 (traducción de García Amado, Juan Antonio, España, Fundación Cultural del Notariado).

Castellanos ruiz, Esperanza (2003): "Reenvío, unidad de la sucesión y armonía internacional de soluciones en el Derecho sucesorio", en: International Law: Revista colombiana de Derecho Internacional ( $N^{\circ}$ 002), pp. 211-260.

Claussen, Lorenz (1995): Gesamtnachfolge und Teilnachfolge (Alemania, Nomos).

CONDE Tejón, Antonio (2004): La cesión global de activo y pasivo como operación de modificación estructural (Procedimiento aplicable, sucesión universal y protección de acreedores) (España, Colegio de Registradores de la Propiedad y Mercantiles de España, Centro de Estudios).

Consejo de Defensa del Estado (1973): Memoria del Consejo de Defensa del Estado correspondiente a los años 1951 a 1973 (Chile, Ed. Andrés Bello).

Contreras Strauch, Osvaldo (2005): Instituciones de Derecho Comercial, Tomo I (Chile, LexisNexis).

Cortés Domínguez, Luis, y Pérez Troya, Adoración (2008): "Fusión de sociedades", en: Uría, Rodrigo, Menéndez, Aurelio, y Olivencia, Manuel (2008): Comentario al régimen legal de las sociedades mercantiles, (Thomson Civitas, España), Tomo IX, Vol. 2.

COURET, Alain (2009): "The Universal Succession as a Technique of Corporate Restructuring: Efficiency and Limits", en: European Company and Financial Law Review (Vol.6, No 4), pp.373-390.

Dauner-LieB, Barbara, y SimON, Stefan (coord.) (2009): Kölner Kommentar zum UmwG (Alemania, Carl Heymanns Verlag).

De Castro y Bravo, Federico (1985): El negocio jurídico (España, Civitas). 
Díez-Picazo, Luis, y Gullón, Antonio (2002): Sistema de Derecho Civil, $10^{\mathrm{a}}$ ed. (España, Tecnos), Volumen I.

Domínguez Benavente, Ramón, y Domínguez Águila, Ramón (1998): Derecho Sucesorio, $2^{a}$ ed. actualizada (Chile, Ed. Jurídica), Tomo I.

Ducci Claro, Carlos (1995): Derecho Civil, Parte General, 4ª ed. actualizada (Chile, Ed. Jurídica).

Duque Domínguez, Justino (1978): "La escisión de sociedades", en: Estudios de Derecho Mercantil en Homenaje a Rodrigo Uría (España, Editorial Civitas S.A.); pp. 125-155.

EBeRHARD, Stefan (1999): La scission de la société anonyme: en droits allemand, américain et suisse (Suiza, Librairie Droz).

EISENBERG, Melvin (1969): "The Legal Roles of Shareholders and Management in Modern Corporate Decisionmaking", en: California Law Review (Vol. 57, $\mathrm{N}^{\circ} 1$ ), pp. 1-181.

Embid IRUjo, José Miguel (1991): "En torno a las modificaciones estructurales de las sociedades mercantiles (fusión, escisión y otros procedimientos similares)", en: Cuadernos de Derecho y Comercio (No 9), pp. 13-37.

Embid Irujo, José Miguel (1991a): "Notas para el estudio de las modificaciones estructurales de las sociedades mercantiles", en: Derecho Mercantil de la Comunidad Europea. Estudios en Homenaje a José Girón Tena (España, Consejo General de los Colegios Oficiales de Corredores de Comercio), pp. 292-302.

Embid IRUjo, José Miguel (2013): "Pasado, presente y futuro del Derecho Europeo de Sociedades", en: lus et Praxis (Vol. 19, № 1), pp. 303-328.

ENGISCH, Karl (2004): La idea de concreción en el derecho y en la ciencia jurídica actuales (Die Idee der Konkretisierung in Recht und Rechtswissenschaft unserer Zeit, -2, Heilderberg, 1968), Estudio preliminar, Epílogo y traducción de Juan José Gil Cremades (España, Ed. Comares).

EsCRIBANO GÁmIR, Cristina (2011): "La responsabilidad de las sociedades beneficiarias de la escisión y de la sociedad parcialmente escindida", en: Documentos de Trabajo del Departamento de Derecho Mercantil (No 2011/36). Disponible en: www.ucm.es/eprints[visitado el 15/02/2013].

Faúndez Ugalde, Antonio (2012): Reorganización empresarial. Derecho Tributario y tributación interna (Chile, Abeledo Perrot Thomson Reuters).

Feliú Segovia, Juan (2008): Manual de Estudio de Títulos, $3^{\text {a }}$ ed. (Chile, Ed. Jurídica). Figueroa Yáñez, Gonzalo (1997): El patrimonio, $2^{a}$ ed. (Chile, Ed. Jurídica).

Flume, Johannes W. (2008): Vermögenstransfer und Haftung. Eine Studie zur Nutzbarmachung der Universalsukzession für die Unternehmenspraxis (Alemania, De Gruyter Recht). 
FuenZALIDA FAIVOVICH, Edmundo (1961): El patrimonio (Chile, Ed. Universitaria). Galimi, Pierpaolo (2005): "Successione a titolo universale nella fusione per incorporazione", en: Diritto e Pratica delle Società (№ 2), pp. 58-62.

GardeAZÁbal del Rıo, Francisco Javier (2001): "Panorámica de las modificaciones estructurales en las sociedades mercantiles", en: Homenaje a Don Antonio Hernández Gil (España, Ed. Centro de Estudios Ramón Areces), Tomo III, pp. 2677-2704.

Gardeazábal del Rıo, Francisco Javier y Martínez Fernández, Tomás (1991): "Problemática que plantean la fusión y el aumento de capital en la sociedad anónima", en: Garrido de Palma, Víctor (dir.) Estudios sobre la sociedad anónima (España, Civitas), pp. 259-322.

Garrido de Palma, Víctor (2012): "La sucesión universal en las modificaciones estructurales", en: Garrido de Palma, Víctor (coord.), Modificaciones Estructurales y Reestructuración Empresarial (España, Tirant Lo Blanch Tratados), pp.144-156.

Garrigues, Joaquín (1949): Tratado de Derecho Mercantil (España, Revista de Derecho Mercantil), Vol. I, Tomo III.

Garrigues, Joaquín (1976): Curso de Derecho Mercantil, 7ª ed. (España, Aguirre), Tomo I.

Garrigues, Joaquín, y URía, Rodrigo (1976): Comentario a la Ley de Sociedades Anónimas, $3^{\text {a }}$ ed. (España, Instituto de Estudios Políticos), Tomo II.

Gevurtz, Franklin (2000): Corporation Law (USA, West Group).

Gil Cremades, Juan José (2004): “Estudio Preliminar", en: Engisch, Karl (2004): La idea de concreción en el derecho y en la ciencia jurídica actuales, Estudio preliminar, Epílogo y traducción de Juan José Gil Cremades (España, Ed. Comares), pp. 17-60.

Giovann, Bonilini (2010): Manuale di diritto ereditario e delle donazioni, $5^{\mathrm{a}}$ ed. (Italia, Utet Giuridica).

Girón Tena, José (1976): Derecho de sociedades, Parte General. Sociedades colectivas y comanditarias (Madrid), Tomo I.

Glover, Stephen (2006): Business Separation Transactions: Spin-Offs, Subsidiary IPOs and Tracking Stock (USA, Law Journal Press).

Gómez PorrúA, Juan (1991): La fusión de sociedades anónimas en el derecho español y comunitario (España, La Ley).

GonZÁlez-Meneses, Manuel (2010): “La Ley 3/2009, sobre modificaciones estructurales de las sociedades mercantiles, y el retroceso del derecho civil", en: El Notario del Siglo XXI (marzo-abril, № 30). Disponible en: www.elnotario. com/egest/portada.php?idSeccion=96[visitado el 02/01/2013].

GuZMán BRITo, Alejandro (2006): "Los vocablos "transferir" y "transmitir" y sus derivados en el "Código Civil de Chile" con especial referencia a la defini- 
ción de título traslaticio de dominio", en: Revista de Derecho de la Pontificia Universidad Católica de Valparaíso (XXVII), pp. 95-103.

Hegemann, Jürgen y QuerbaCH, Torsten (2007): Umwandlungsrecht. Grundlagen und Steuern (Alemania, Gabler).

HeRnÁNDEZ AdAsme, Ricardo (2000): Fusión, transformación y división de sociedades anónimas, Efectos Tributarios (Chile, Ediciones Jurídicas La Ley).

IGlesias Coronel, Patricio (2003): Transformación, división y fusión de sociedades anónimas, Memoria para optar al grado de Licenciado en Ciencias Jurídicas y Sociales, Universidad de Chile.

JACOBS, Robert (1967): "The anatomy of a spin-off", en: Duke Law Journal (Vol. $\left.1967, \mathrm{~N}^{\circ} 1\right)$, pp. 1-38.

KAlLmeYER, Harald et al (2010): Umwandlungsgesetz, 4. Auflage (Alemania, Otto Schmidt).

KESSLER, Jürgen y KüHnBERGER, Manfred (coord.) (2009): Umwandlungsrecht. Kompakt-Kommentar (Alemania, Schäffer-Poeschel).

KraAkman, Reinier et al (2009): The Anatomy of Corporate Law: A Comparative and Functional Approach, $2^{\text {nd }}$ ed. (Oxford University Press).

Larenz, Karl (2001): Metodología de la Ciencia del Derecho, $2^{\mathrm{a}}$ ed. (Methodenlehre der Rechtswissenschaft), -2, Berlín, 1980 (traducción de Rodríguez Molinero, España, M., Ariel Derecho).

Largo GIL, Rita (1997): "Las modificaciones estructurales de las sociedades según la Dirección General de los Registros y del Notariado", en: Revista de Derecho de Sociedades (№ 9), pp. 143-185.

LEÓN HURTADO, Avelino (1991): La voluntad y la capacidad en los actos jurídicos, $4^{a}$ ed. actualizada (Chile, Ed. Jurídica).

LEÓN SANZ, Francisco (1994): "Derecho proyectado alemán sobre modificaciones estructurales de las sociedades mercantiles ("Referentenentwurf Gesetz zur Bereinigung des Umwandlungsrechts" de 15 de abril de 1992)", en: Revista de Derecho de Sociedades (II, № 2), pp. 448-453.

LIRA URQUieta, Pedro (1948): La partición de bienes (Chile, Ed. Jurídica).

Lyon Puelma, Alberto (2003): Personas Jurídicas (Chile, Ediciones Universidad Católica).

MANTOVANI, Andrea (2008): Fusione, scissione e limiti alla circolazione dei beni, Tesi di dottorato, Università degli Studi Roma Tre.

Martín García, José Manuel (2008): "La Escisión", en: Sánchez Álvarez, Manuel (coord.), Estudios Jurídicos sobre Operaciones de Reestructuración Societaria (España, Garrigues, Thomson Aranzadi), pp. 121-164.

MARTY, Richard (1999): "Restructuration de sociétés, transmission universelle du patrimoine et droit du cautionnement", en: Revue française de comptabilité (No 312), pp. 69-76. 
MaulBetsCh, Hans-Christoph et al (2008): Umwandlungsgesetz, Heidelberger Kommentar (Alemania, Hüthig Jehle Rehm).

MontOro Ballesteros, Alberto (1982): "Análisis estructural y conocimiento jurídico (Notas sobre la significación, las posibilidades y los límites del estructuralismo en el pensamiento jurídico), en: Anales de Derecho (No 3), pp. 7-60.

Morles Hernández, Alfredo (2007): Curso de Derecho Mercantil, Introducción, La Empresa, El Empresario, 9a ed. (Venezuela, Universidad Católica Andrés Bello), Tomo 1.

Morand Valdivieso, Luis (2004): Sociedades, $3^{\text {a }}$ edición actualizada con la normativa de la Ley No 19.705 (Ley de Opas) de 2000 (Chile, Ed. Jurídica).

Motos Guirao, Miguel (1953): Fusión de sociedades mercantiles (España, Ed. Revista de Derecho Privado).

Niño TeJEDA, Eduardo (1993-1994): "Esquema sobre el patrimonio", en: Revista de Derecho de la Universidad Católica de Valparaíso (XV), pp. 153-164.

NoBILI, Raffaele (1957): "La scorporazione delle societá nella recente dottrina italiana", en: Rivista del Diritto Commerciale e del Diritto Generale Delle Obligazioni ( $\left.\mathrm{N}^{\circ} 1-2\right)$, pp. 34-39.

O'Callaghan, Xavier (1999): Compendio de Derecho Civil, $5^{\text {a }}$ ed. (España, Edersa), Tomo $V$, Derecho de Sucesiones.

Oesterle, Dale (2005): The Law of Mergers and Acquisitions, $3^{\text {rd }}$ ed. (USA, Thomson/West).

Olavarría Aqueveque, Óscar (2004): Elementos del Derecho Sucesorio Chileno (Chile, LexisNexis).

Olivencia Ruiz, Manuel (1978): "La confusión de patrimonios y el artículo 285 del Código de Comercio", en: AA.VV., Estudios de Derecho Mercantil en homenaje a Rodrigo Uría (España, Ed. Civitas, España), pp. 497-524.

OtAegui, Julio (1981): Fusión y escisión de sociedades comerciales (Argentina, Editorial Ábaco de Rodolfo Depalma).

Peñaillllo Arévalo, Daniel (2002): Los bienes. La propiedad y otros derechos reales, $3^{\text {a }}$ ed. (Chile, Ed. Jurídica de Chile).

Pérez Fontana, Sagunto (1970): La fusión de sociedades (Uruguay).

Pérez Milla, José (1996): Fusión internacional de Sociedades Anónimas en el Espacio Jurídico Europeo (España, Ed. Aranzadi).

Puelma AcCorsI, Álvaro (2001): Sociedades, $3^{\text {a }}$ ed. actualizada y aumentada (Chile, Ed. Jurídica), Tomos I y II.

Puga Vial, Juan Esteban (2011): La Sociedad Anónima y otras sociedades por acciones en el Derecho chileno y comparado (Chile, Ed. Jurídica).

Quijano González, Jesús y Esteban Ramos, Luisa Ma (2009): "Tutela de los acreedores: la responsabilidad de las sociedades que participan en la escisión", en: Rodríguez Artigas, Fernando (coord.), Modificaciones Estructurales de 
las Sociedades Mercantiles (Aranzadi Thomson Reuters, España), Tomo II, Traslado internacional del domicilio social, Escisión, Cesión global de activo y pasivo, Otras cuestiones, pp. 553-626.

Quintana Bravo, Fernando (2001): Prudencia y justicia en la aplicación del Derecho (Chile, Ed. Jurídica).

RAFFRAY, Ronan (2011): La transmission universelle du patrimoine des personnes morales, Nouvelle Bibliothèque de Thèses (Francia, Dalloz).

ReCORDOn, Pierre-Alain (1974): La protection des actionnaires lors des fusions et scissions de sociétés en droit suisse et en droit français (Suiza, Librairie de I'université Georg \& Cie S.A.).

Ríos LABBÉ, Sebastián (2008): "Las cesiones legales de contrato. Una contribución al régimen de la cesión convencional de contrato", en: Mantilla Espinosa, Fabricio, y Pizarro Wilson, Carlos (coord.) Estudios de Derecho Privado en Homenaje a Christian Larroumet (Colombia, Ed. Universidad El Rosario); pp. 169-197.

Rojas Castañeda, Aída (2010): "Escisión de sociedades mercantiles", en: Alegatos ( $N^{\circ} 16$, septiembre-diciembre), pp. 801-816.

RIVERA RESTREPO, José (2011): "Una mirada a la doctrina de la causa y sus distintas versiones en el Código Civil chileno", en: Revista de Derecho (Universidad Católica del Norte) (Año 18, № 2), pp. 305-346.

RUPERTO, Cesare (1950): "La successione universale tra vivi nel nostro diritto", en: Rivista del Diritto Commerciale e del Diritto Generale Delle Obligazioni (No 3-4), pp. 123-150.

SAndoval López, Ricardo (1986): "Acerca del objeto en la sociedad anónima", en: Revista de Derecho, Universidad de Concepción ( $\left.N^{\circ} 179\right)$, pp. 75-82.

SANDOval López, Ricardo (2010): "La división o escisión de sociedades", en: Anuario de Derecho Comercial y Marítimo (№ 1/2009), pp. 389-403.

SANTAGata, Carlo (1964): La fusione tra società (Italia, Morano Editore).

Sarale, Marcella (2011): "Le scissioni", en: Cottino, G. (dir.), Trattato di Diritto Commerciale, Volume V, 2, Le operazioni societarie straordinarie (Italia, Giuffré editore), pp. 601-669.

SAVIGnY, Friedrich Karl von (1879): Sistema del Derecho Romano Actual, T. II (España, F. Góngora y Compañía Editores).

SCHMIDT, Karsten (1995): "Sucesión universal en virtud de negocio jurídico. Comprobación de la eficacia de una institución de derecho civil en el derecho de la empresa", en: Revista Jurídica del Notariado (No 15), pp. 197-239.

Sequeira Martín, Adolfo (1993): Comentarios a la ley de sociedades anónimas, dirigidos por Fernando Sánchez Calero (España, Ed. Revista de Derecho Privado), Tomo VII, Transformación, fusión y escisión. 
SIEGEL, Stanley (1966): "When Corporations Divide: A Statutory and Financial Analysis", en: Harvard Law Review (Vol. 79, № 3), pp. 534-570.

Silva Segura, Enrique (1985): Acciones, actos y contratos sobre cuota, $2^{a}$ ed. (Chile, Ed. Jurídica).

Solari Costa, Osvaldo (1996): Fusión y escisión nacional y transnacional de sociedades (Argentina, Ad-Hoc).

SOlARI Costa, Osvaldo (2004): El acto de fusión societaria (Argentina, Ed. Astrea).

SOlOVERA, Christian (1996): Transformación, fusión y división de sociedades (Doctrina, Legislación y Jurisprudencia), Memoria de la Universidad Central.

Soza Ried, María de los Ángeles (1999): "Adquisición patrimonial y sucesión: una precisión de conceptos a partir del Derecho Romano", en: Revista de Estudios Histórico-Jurídicos (№ 21), pp. 75-101.

Stengel, Arndt (1995): "The New German Business Transformation Act", en: $\operatorname{ICCLR}\left(\mathrm{N}^{\circ} 6,3\right)$, pp. 86-92.

Torres Zagal, Oscar (2006): Derecho de Sociedades (Chile, LexisNexis).

TRíAs, Miguel (2001): "La fusión y operaciones de similar alcance", en: AA.VV., Las operaciones societarias de modificación estructural (España Esade, Tirant lo Blanch), pp. 71-91.

URENDA BILICIC, Nicolás (2004): División y fusión de sociedades. Efectos tributarios (Chile, Ed. Jurídica La Ley).

Vallet de Gortisolo, Juan (2004): "Donaciones, mejoras, dispensas de colación", en: AA.VV., Libro homenaje al profesor Manuel Albaladejo García, Volumen 1 (España, Universidad de Murcia, Servicio de Publicaciones), pp. 4903-4914.

Vasconcelos Allende, Guillermo de J. (1995): "Notas para el estudio de la escisión de sociedades", en: Revista Jurídica. Anuario del Departamento de Derecho de la Universidad Iberoamericana ( $\left.\mathrm{N}^{\circ} 23\right)$, pp. 471-508.

Vásquez Palma, María Fernanda (2013): Sociedades. Comerciantes, empresas, grupos de empresas y otros sujetos del Derecho Comercial (Chile, Legalpublishing-Thomson Reuters).

Vial Del Río, Víctor (2003): Teoría general del acto jurídico, 5ª ed. actualizada (Chile Ed. Jurídica).

VILLALÓN EZQUeRro, Francisco Javier (1986): "La escisión: la realidad ante la ley", en: Cuadernos del Instituto de Investigaciones Jurídicas (Año 7, № 3), pp. 1139-1176.

VILleGas, Carlos Gilberto (1995): Tratado de las sociedades (Chile, Ed. Jurídica). Waters, Donovan (1990): "Convention on the law applicable to succession to the estates of deceased persons, Explanatory Report" (Países Bajos, Permanent Bureau of the Hague Conference on Private International Law). 
WolfF, Herman Jr. (1953): "Divisive reorganizations as affected by the Revenue Act of 1951", en: Taxes (Vol. 31), pp. 716 y ss.

NORMAS JURÍDICAS CITADAS

Código CiviL

Ley $N^{\circ} 18.046$, sobre Sociedades Anónimas, Diario Oficial de 22 de octubre de 1981.

Ley $N^{\circ} 19.705$, regula las ofertas públicas de adquisición de acciones (opas) y establece régimen de gobiernos corporativos, Diario Oficial de 20 de diciembre de 2000.

Ley $N^{\circ} 19.857$, que autoriza la constitución de la Empresa Individual de Responsabilidad Limitada (EIRL), Diario Oficial de 11 de febrero de 2003.

Ley $\mathrm{N}^{0} 20.500$, sobre asociaciones y participación ciudadana en la gestión pública, Diario Oficial de 16 de febrero de 2011.

Ley $N^{\circ} 17.073$, establece normas tributarias que señala, Diario Oficial de 31 de diciembre de 1968.

Ley $N^{\circ} 16.272$, sobre Timbres, Estampillas y Papel Sellado, Diario Oficial de 04 de agosto de 1965.

Decreto № 1.995, de 1970, del Ministerio de Hacienda, que modificó el Reglamento de Sociedades Anónimas Nacionales y Extranjeras, aprobado por Decreto 4.705, de 30 de noviembre de 1946, Diario Oficial de 17 de septiembre de 1970.

Decreto $N^{\circ} 702$, de 2011, del Ministerio de Hacienda, aprueba el Nuevo Reglamento de Sociedades Anónimas, Diario Oficial de 06 de julio de 2012.

\section{JURISPRUDENCIA CITADA}

CHILE

Inversiones Tocopilla Dos B S.A. con Ilustre Municipalidad de Las Condes (2012): Corte Suprema, Rol № 8354-2011, de 22 de noviembre de 2012 (casación en el fondo). Disponible en: www.poderjudicial.cl.

Banco Santander-Chile con Baeza Roa Benjamín y otros (2010): Corte Suprema, Rol No 5143-2010, de 12 de agosto de 2010 (casación forma y fondo). Disponible en: www.poderjudicial.cl.

Inspección Comunal del Trabajo de Santiago Norte con Lan Airlines S.A. (2009): Corte Suprema, Rol No 1.347-2009, de 6 de agosto de 2009 (casación forma y fondo). Disponible en: www.poderjudicial.cl.

Paneles Arauco S.A. con Servicio de Impuestos Internos (2011): Corte Suprema, Rol No 1121-2009, de 14 de junio de 2011 (casación fondo). Disponible en: www.poderjudicial.cl. 
María Parot Gamboa con Sociedad Agrícola Las Tejas Limitada (2011): Corte de Apelaciones de Talca, Roles № 627 y 628/2010, acumulados, de 1 de junio de 2011 (apelación). Disponible en: www.poderjudicial.cl.

Banco Bhif con Sergio Fernández Rojas (1994): Corte de Apelaciones de Santiago, de fecha 23 de marzo de 1994 (apelación), № Legal Publishing: 28874.

Banco Bhif con Cidef S.A. (1999): 24 Juzgado Civil de Santiago, Rol C-8221999, de fecha 9 de mayo de 2002. Disponible en: www.poderjudicial.cl.

\section{ITALIA}

Corte d'Appello di Genova, 9 febbraio 1956, pres. Lorenzi, Est. Miani S.r.l. C.I.S.A.

\section{FRANCIA}

Cass. Com., 20 juin 1966, pourvoi No JURITEXT000006971809, Bull. civ. $\mathrm{N}^{\circ} 312$.

Cass. Com., 7 décembre 1966.

Cass. Com., 20 février 2005.

SuIZA

Bundesgericht (4C.385/2005) (31/01/2006). 